Check for updates

Cite this: Dalton Trans., 2020, 49 11756

\section{Synthesis and photoluminescence of three bismuth(III)-organic compounds bearing heterocyclic $\mathbf{N}$-donor ligands $\uparrow$}

\author{
Alyssa K. Adcock, ${ }^{a}$ R. Lee Ayscue, III, (D) † Leticia M. Breuer, ${ }^{a}$ Chloe P. Verwiel, ${ }^{a}$ \\ Alexander C. Marwitz, (D) a Jeffery A. Bertke, (D) a Valérie Vallet, (iD b Florent Réal (iD b \\ and Karah E. Knope (iD *a
}

\begin{abstract}
Three bismuth(III)-organic compounds, $\left[\mathrm{Bi}_{4} \mathrm{Cl}_{8}(\mathrm{PDC})_{2}(\text { phen })_{4}\right] \cdot 2 \mathrm{MeCN}$ (1), $\left[\mathrm{BiCl}_{3}(\text { phen })_{2}\right]$ (2), and $\left[\mathrm{Bi}_{2} \mathrm{Cl}_{6}(\text { terpy })_{2}\right]$ (3), were prepared from solvothermal reactions of bismuth chloride, 2,6-pyridinedicarboxylic acid $\left(\mathrm{H}_{2} \mathrm{PDC}\right)$, and 1,10-phenanthroline (phen) or $2,2^{\prime} ; 6^{\prime}, 2^{\prime \prime}$-terpyridine (terpy). The structures were determined through single crystal $X$-ray diffraction and the compounds were further characterized via powder X-ray diffraction, Raman and infrared spectroscopy, and thermogravimetric analysis. The photoluminescence properties of the solid-state materials were assessed using steady state and time-dependent techniques to obtain excitation and emission profiles as well as lifetimes. The compounds exhibit visible emission ranging from the yellow-green to orange region upon UV excitation. Theoretical quantum mechanical calculations aimed at elucidating the observed emissive behavior show that the transitions can be assigned as predominantly ligand-to-ligand and ligand-to-metal charge transfer transitions. The solid-state structural chemistry, spectroscopic properties, and luminescence behavior of the bismuth compounds are presented herein.
\end{abstract}

Received 3rd July 2020

Accepted 6th August 2020

DOI: $10.1039 / d 0 d t 02360 d$

rsc.li/dalton variable stereochemical activity. This results in a flexible coordination environment ranging from a hemidirected to holodirected coordination sphere, a range of coordination numbers, and thus, the potential for novel structuretypes. ${ }^{14,21-27}$ Yet, such structural diversity combined with the limited solubility and hydrolytic propensity of many Bi salt starting materials can provide significant challenges for controlled synthesis and structure prediction. As such, developing fundamental knowledge of the synthesis and structural chemistry of bismuth-organic-based phases is not only crucial for overcoming such challenges but also can provide key insight into the role that structural features have on materials properties such as luminescence.

Several luminescent bismuth-organic compounds have been reported to date; $;^{12,13,19,22,28,29}$ however, identification of the energy transfer pathways is often non-trivial; a number of charge transfer (CT) and/or ligand emission processes can play a role in the resulting luminescence. Bismuth-organic compounds have been reported to exhibit luminescence across a range of colors including "white" light emission. ${ }^{14}$ The origins of these emissive transitions have been attributed to ligand-tometal charge transfer (LMCT), metal-to-ligand charge transfer (MLCT), intraligand transitions $\left(\mathrm{n} \leftarrow \pi^{*}\right) /\left(\pi \leftarrow \pi^{*}\right)$ that are noticeably shifted from the free ligand emission, and/or intraconfigurational ${ }^{1} \mathrm{P}_{1} \rightarrow{ }^{1} \mathrm{~S}_{0}$ and ${ }^{3} \mathrm{P}_{1} \rightarrow{ }^{1} \mathrm{~S}_{0}$ transitions originating 
from the $6 \mathrm{~s}^{2}$ closed shell $\mathrm{Bi}^{3+}$ metal center. ${ }^{14-19,28,30}$ Intervalence charge transfer has also been recently reported for several Bi systems. ${ }^{22,29}$ Additionally, the luminescence behavior of several halobismuthates have been attributed to a combination of metal-centered sp excited states and halogento-metal charge transfer (XMCT). ${ }^{12,31}$ Given the number of plausible energy transfer pathways that generally produce similar broad visible emission, a combined experimental and computational approach is essential for identifying structureproperty relationships and elucidating the underlying luminescence mechanisms.

In this work, three compounds built from molecular Bi(III)chloride complexes capped by $\mathrm{N}$-donor ligands, 2,2',6,2"-terpyridine (terpy), 1,10-phenantroline (phen), and 2,6-pyridinedicarboxylic acid (PDC), were synthesized under solvothermal conditions. Selection of the ligands was based on several factors. Beyond their precedence in luminescent materials research, ${ }^{32-35}$ these ligands have been shown to restrict dimensionality through capping coordination modes to yield molecular units. $^{36-40}$ Moreover, the aromaticity of the ligands may promote supramolecular interactions such as $\pi-\pi$ stacking, which have been shown to impact the materials properties of hybrid inorganic-organic complexes. ${ }^{41}$ The obtained compounds, $\left[\mathrm{Bi}_{4} \mathrm{Cl}_{8}(\mathrm{PDC})_{2}(\text { phen })_{4}\right] \cdot 2 \mathrm{MeCN}$ (1), $\left[\mathrm{BiCl}_{3}(\text { phen })_{2}\right]$ (2), and $\left[\mathrm{Bi}_{2} \mathrm{Cl}_{6}(\text { terpy })_{2}\right](3)$, were structurally characterized via X-ray diffraction studies and found to vary in nuclearity from mononuclear species (2) to dimeric units (3) to pseudo-tetrameric complexes (1). To the best of our knowledge, the pseudo-tetramers observed in $\mathbf{1}$, which are bridged through carboxylate linkages and exhibit long $\mathrm{Bi} \cdots \mathrm{Cl} \cdots \mathrm{Bi}$ interactions between adjacent dimers, are unique within bismuth structural chemistry. Though the structure of compound 2 was previously described by White et al., the photoluminescence properties of this phase were not reported. ${ }^{42}$ As such, 2 is included in this report to aid in the discussion of relevant structure-property relationships. The photoluminescence properties of 1-3 were explored through steady-state and time-dependent techniques. Each compound displayed visible light emission with room temperature lifetimes on the order of $10^{-6} \mathrm{~s}$. Quantum mechanical calculations using structural models obtained from the experimentally determined single-crystal structures were performed to better understand the origins of the observed emissive pathways. The excitation and emission transitions for 1-3 are attributed to MLCT and LMCT pathways, respectively. Furthermore, corresponding electron density calculations suggest these CT pathways are facilitated between Bi-halide subunits and $\mathrm{N}$-donor ligands. Through this investigation, valuable insight into structural features that potentially impart and/or influence luminescence properties is provided.

\section{Experimental section}

\section{Materials}

Bismuth(III) chloride (Acros Organic, 98+\%), 2,6-pyridinedicarboxylic acid (Alfa Aesar, 98\%), 2,2';6',2"-terpyridine (Alfa Aesar,
97\%), 1,10-phenanthroline (Acros Organics, 99+\%), ethanol (Warner Graham Company), and acetonitrile (Fisher) were used as received. Nanopure water $(\leq 0.05 \mu \mathrm{S}$; Millipore, USA) was used in all experiments.

\section{Synthesis}

$\left[\mathrm{Bi}_{4} \mathrm{Cl}_{\mathbf{8}}(\mathrm{PDC})_{2}(\text { phen })_{4}\right] \cdot 2 \mathrm{MeCN} \quad$ (1). Bismuth chloride (0.0313 grams, $0.1 \mathrm{mmol}$ ), 2,6-pyridinedicarboxylic acid (0.0165 grams, $0.1 \mathrm{mmol}$ ), 1,10-phenanthroline (0.0180 grams, $0.1 \mathrm{mmol})$, and acetonitrile $(3 \mathrm{~mL})$ were loaded into a Teflonlined stainless-steel autoclave. The autoclave was heated statically at $150^{\circ}$ for 24 hours in an isothermal oven, then removed from the oven, and allowed to slow cool to room temperature over four hours. The reaction vessel was left undisturbed for one week after which the products were collected, washed with ethanol, and allowed to dry under ambient conditions. Colorless, thick needles of $\mathbf{1}$ were obtained along with a minor impurity identified as 2 via PXRD. Manual separation of 1 based on morphology allowed for yield estimation and subsequent bulk characterization. Note that crystals of both 1 and 2 were observed when the reaction vessel was opened immediately after cooling to room temperature; however, manual separation was not successful in these trials with shorter cooling times. Estimated yield of 1: 40\% (based on Bi). Elemental analysis for $\mathrm{C}_{66} \mathrm{H}_{44} \mathrm{Bi}_{4} \mathrm{Cl}_{8} \mathrm{~N}_{12} \mathrm{O}_{8}$ : Calc. (Obs.): C, 35.18 (34.95); H, 1.98 (1.74); N, 7.46 (7.17\%). Raman 1: $\tilde{\nu}=1658,1590,1518,1453,1421$, 1300, 1105, 1053, 1027, 724, 557, 518, 422, 286, $250 \mathrm{~cm}^{-1}$.

$\left[\mathrm{BiCl}_{3}(\text { phen })_{2}\right]$ (2). Although 2 could be prepared solvothermally as a minor product as described above, in order to obtain sufficient product for bulk characterization the compound was prepared following a published synthesis. ${ }^{42}$ Bismuth chloride $(0.25 \mathrm{~g}, 0.79 \mathrm{mmol}), 1,10$-phenanthroline (0.43 grams, $2 \mathrm{mmol})$, and acetonitrile $(20 \mathrm{~mL})$ were heated under reflux with constant stirring (500 rpm). After two hours the white solid that was initially observed gradually turned faint pink; the pink solid was isolated via filtration. Further steps as described in the published synthesis to obtain single crystals including extraction into dimethyl sulfoxide/dichloromethane and evaporation were not performed, as single crystals sufficient for structure determination were obtained from the synthesis that yielded 1. Yield: $87 \%$ (based on $\mathrm{Bi}$ ). Elemental analysis for $\mathrm{C}_{24} \mathrm{H}_{16} \mathrm{BiCl}_{3} \mathrm{~N}_{4}$ : Calc. (Obs.): C, 42.65 (42.77); H, 2.39 (2.26); N, 8.29 (8.28\%).

$\left[\mathbf{B i}_{2} \mathbf{C l}_{6}(\text { terpy })_{2}\right]$ (3). Bismuth chloride $(0.0319 \mathrm{~g}, 0.1 \mathrm{mmol})$, 2,6-pyridinedicarboxylic acid (0.0164 g, $0.1 \mathrm{mmol}), 2,2^{\prime}: 6^{\prime}, 2^{\prime \prime}-$ terpyridine $(0.0236 \mathrm{~g}, 0.1 \mathrm{mmol})$, and acetonitrile $(5 \mathrm{~mL})$ were loaded into a $23 \mathrm{~mL}$ Teflon-lined stainless-steel autoclave. The autoclave was heated statically at $150^{\circ}$ for five days in an isothermal oven, after which the autoclave was removed from the oven and allowed to cool to room temperature overnight. Large, rectangular prisms of $\mathbf{3}$ were collected, washed with ethanol, and allowed to dry under ambient conditions. Yield: $83 \%$ (based on $\mathrm{Bi}$ ). Elemental analysis for $\mathrm{C}_{30} \mathrm{H}_{22} \mathrm{Bi}_{2} \mathrm{Cl}_{6} \mathrm{~N}_{6}$ : Calc. (Obs.): C, 32.83 (32.86); H, 2.02 (2.13); N, 7.66 (7.70\%). Raman $3 \tilde{\nu}=1591,1563,1497,1482$, 1456, 1331, 1302, 1288, 1116, 1080, 1042, 1005, 827, 721, 655, 403, 301, 271, $250 \mathrm{~cm}^{-1}$. 


\section{Bulk characterization methods}

Powder X-ray diffraction data were collected for bulk samples from which compounds 1-3 were isolated (Fig. S4-S8†) using $\mathrm{Cu}-\mathrm{K} \alpha$ radiation $(\lambda=1.542 \AA)$ on a Rigaku UltimaIV with a rotation speed of 1 degrees per min from 3-40 degrees $2 \theta$. Combustion elemental analysis was performed on a PerkinElmer Model 2400 Elemental Analyzer for C, H, and N determination. Thermogravimetric analyses were conducted for $\mathbf{1}$ and $\mathbf{3}$ on a TA Instruments Q50 Thermogravimetric Analyzer under flowing air $\left(60 \mathrm{~mL} \mathrm{~min}{ }^{-1}\right)$ from 50 to $600{ }^{\circ} \mathrm{C}$ with a step speed of $5{ }^{\circ} \mathrm{C} \min ^{-1}$ (Fig. S18 and S19†). UV-vis absorption spectra for solid samples of 1-3 were collected on an Agilent Technologies Cary 5000 UV/Vis-NIR instrument using a diffuse reflectance attachment. Spectra (Fig. S15-S17†) were collected over 200-800 $\mathrm{nm}$ using the Cary WinUV program. Raman spectra were collected on single crystals pulled from the bulk sample using an excitation source of $532 \mathrm{~nm}$ (maximum power $=100 \mathrm{~mW}$ ) on a Horiba LabRAM HR Evolution Raman Spectrometer. Spectra of 1 and 3 (Fig. S22 and S23†) were recorded from 200 to $2200 \mathrm{~cm}^{-1}$ using 20 accumulations and a laser power between 3.2 to $10 \%$.

\section{Structure determination via single crystal X-ray diffraction}

Single crystals of 1-3 were isolated from the bulk samples and mounted in N-paratone on MiTeGen micromounts. Single crystal X-ray diffraction data were collected at 100(2) K on a Bruker D8 Quest diffractometer equipped with an I $u$ S X-ray source (Mo-K $\alpha$ radiation; $\lambda=0.71073 \AA$ ) and a Photon 100 detector. Each data set was integrated using the SAINT software package included with APEX3. ${ }^{43,44}$ An absorption correction was applied using a multi-scan technique in SADABS. ${ }^{44}$ The structures were then solved using direct methods via SHELXT and refined by full-matrix least-squares on $F^{2}$ using the SHELXL software in SHELXLE. ${ }^{45,46}$ Crystallographic data are provided in Table 1, and full refinement details as well as CIF data are available as ESI. $\dagger$ CIF data for 1-3 were also submitted to the Cambridge Crystallographic Data Centre (CCDC), http://www.ccdc.cam.ac.uk/by, and may be obtained by referencing numbers 1841302-1841304. $\dagger$ While the structure of 2 at $295 \mathrm{~K}$ was previously reported, ${ }^{42}$ a low temperature dataset for 2 was collected at $100 \mathrm{~K}$ for the sake of comparison with the structures reported herein. Intermolecular interactions for all compounds were assessed using the PLATON software suite. ${ }^{47}$

\section{Luminescence measurements}

Excitation and emission spectra were collected on a Horiba PTI QM-400 Spectrofluorometer at room temperature on ground solid samples (Fig. S9-S11†). Long pass filters were used to remove harmonic signatures. Time-resolved measurements to determine lifetime values were acquired at room temperature using a Xenon flash lamp as the average of 10000 shots. Decay curves were plotted and fit using Origin Pro 8.5 (Fig. S12-S14 $\dagger$ ). Lifetime values given are the average of three independent determinations taken at the maximum excitation and emission wavelengths.
Table 1 Crystallographic structure refinement details for 1-3

\begin{tabular}{|c|c|c|c|}
\hline & 1 & 2 & 3 \\
\hline $\begin{array}{l}\text { Chemical } \\
\text { formula }\end{array}$ & $\mathrm{C}_{66} \mathrm{H}_{44} \mathrm{Bi}_{4} \mathrm{Cl}_{8} \mathrm{~N}_{12} \mathrm{O}_{8}$ & $\mathrm{C}_{24} \mathrm{H}_{16} \mathrm{BiCl}_{3} \mathrm{~N}_{4}$ & $\mathrm{C}_{30} \mathrm{H}_{22} \mathrm{Bi}_{2} \mathrm{Cl}_{6} \mathrm{~N}_{6}$ \\
\hline $\mathrm{MW}\left(\mathrm{g} \mathrm{mol}^{-1}\right)$ & 2252.67 & 675.75 & 1097.21 \\
\hline$T(\mathrm{~K})$ & $100(2)$ & $100(2)$ & $100(2)$ \\
\hline$\lambda(\operatorname{Mo~K} \alpha)$ & 0.71073 & 0.71073 & 0.71073 \\
\hline$\mu\left(\mathrm{mm}^{-1}\right)$ & 10.813 & 8.433 & 11.446 \\
\hline Crystal system & Triclinic & Monoclinic & Monoclinic \\
\hline Space group & $P \overline{1}$ & $P 2_{1} / c$ & $P 2_{1} / n$ \\
\hline$a(\AA)$ & $9.7898(6)$ & $9.6115(3)$ & $12.7368(6)$ \\
\hline$b(\AA)$ & $13.7846(13)$ & $31.7985(1)$ & $9.4838(4)$ \\
\hline$c(\AA)$ & $27.4465(18)$ & $7.5977(2)$ & $13.6313(6)$ \\
\hline$\alpha\left({ }^{\circ}\right)$ & $102.725(2)$ & 90 & 90 \\
\hline$\beta\left({ }^{\circ}\right)$ & $90.442(2)$ & 109.328(1) & $102.0880(10)$ \\
\hline$\gamma(0)$ & $110.737(2)$ & 90 & 90 \\
\hline Volume $\left(\AA^{3}\right)$ & $3363.9(4)$ & $2191.22(11)$ & $1610.06(12)$ \\
\hline$Z$ & 2 & 4 & 4 \\
\hline$R_{\text {int }}$ & $\mathrm{NA}^{a}$ & 0.0224 & 0.0567 \\
\hline$R(I>2 \sigma)$ & 0.0270 & 0.0152 & 0.0247 \\
\hline $\mathrm{w} R_{2}$ & 0.0627 & 0.0317 & 0.0635 \\
\hline GooF & 1.076 & 1.166 & 1.099 \\
\hline CCDC number & 1841302 & 1841303 & 1841304 \\
\hline
\end{tabular}

${ }^{a}$ The refinement of $\mathbf{1}$ was processed as a two component twin and therefore, an $R_{\text {int }}$ is not reported. Moreover, compound 2 (295 K) was previously reported and can be found by referencing PURQUO. ${ }^{42}$

\section{Computational studies}

Structural models obtained from the single crystal structures were used to calculate the absorption spectra in an effort to identity the transitions involved in the observed photoluminescence spectra. Clusters of various sizes were rendered and used for analysis, starting from a single molecular unit to larger systems (dimer, trimer, and pseudo-tetramer). All spectra were computed using a similar approach proposed by Sorg et al. ${ }^{17}$ based on single point calculations using a current development version of the ORCA 4.1.2 program package. ${ }^{48,49}$ The calculations rely on the use of the CAM-B3LYP functional, a hybrid functional with long-range separation, to compute the density of the compound, ${ }^{50}$ associated to def2-SVP basis set for all atoms, ${ }^{51}$ and a Relativistic Small Core Effective Pseudopotential for $\mathrm{Bi}^{52}$ To accelerate the calculations, two approximations were used: the RI and chain-of-spheres (COSX) approximations (grid X5). ${ }^{53,54}$ The absorption energies and oscillator strengths were computed by means of the sTDA (simplified Tamm-Dancoff approach) method, ${ }^{55-57}$ which allows a reasonable qualitative description of large-system spectra. Spin-orbit coupling has been neglected as no change in the spectral envelopes was observed for the monomer $\mathrm{BiCl}_{3}$ (phen) $)_{2}$ in compound $\mathbf{1}$ (see Discussion in section VII of the ESI $\dagger$ ). An energy cut-off at $5 \mathrm{eV}$ was used, and spectra were normalized over a region between 250 up to $450 \mathrm{~nm}$. For the non-zero absorption states, a Lorentzian function was added on top of each peak, with various widths in order to account for the natural broadening observed at ambient temperature.

Additional analysis was performed using the ADF package. ${ }^{58-60}$ Analysis of the bonds between the metal and the ligands were realized using the ETS-NOCV (Extended Transition State Natural Orbitals for Chemical Valence) ana- 
lysis method available in the ADF package, with the PBE0 functional. The molecular complex was partitioned into two fragments, the first one being the $\mathrm{BiCl}_{3}$ subunit and the second the phen groups. ${ }^{61,62}$

\section{Results and discussion}

\section{Synthetic considerations}

Synthetic avenues to access bismuth-based materials can be challenging, in part, due to the limited solubility of bismuth precursors and the hydrolytic instability of bismuth. The reaction that yielded 1 also produced 2 as a minor impurity; therefore, manual separation of the phases was necessary to perform subsequent characterization and achieve phase purity of 1. Extensive variation of reaction parameters was performed in an attempt to afford a phase-pure product of $\mathbf{1}$ but proved unsuccessful. Although it was not incorporated into the solidstate structure of $3,2,6-\mathrm{H}_{2}$ PDC was added to the reaction and seemingly enabled improved crystallization of $\mathbf{3}$ as large block crystals. Absent this organic "spectator", a microcrystalline powder of 3, along with a BiOCl impurity that originates from partial hydrolysis of $\mathrm{BiCl}_{3}$, was obtained (Fig. S8 $\dagger$ ). Solvothermal reactions were used to help mitigate formation of bismuth oxychloride. Furthermore, the addition of $\mathrm{H}_{2} \mathrm{PDC}$ may help drive the assembly of $\mathbf{3}$ and subsequently preclude formation of $\mathrm{BiOCl}$; although, the exact role of $\mathrm{H}_{2} \mathrm{PDC}$ is unknown. Reactions with other organic species $\left(2,5-\mathrm{H}_{2} \mathrm{PDC}\right.$ and $3,4-\mathrm{H}_{2} \mathrm{PDC}$ ) were performed in attempt to obtain other novel phases; however, 3 was the only phase observed.

\section{Structure descriptions}

The single crystal structures of 1-3 were determined at $100 \mathrm{~K}$ using single crystal X-ray diffraction. The structure of 2 at $295 \mathrm{~K}$ has been previously reported; however, for the sake of comparison with 1 and 3, a low temperature dataset was collected at $100 \mathrm{~K}$. The structure of each compound consists of discrete molecular units, varying in nuclearity from mono- nuclear moieties in 2 to dimeric units in 3 to pseudo-tetrameric species in $\mathbf{1}$.

$\left[\mathrm{Bi}_{4} \mathrm{Cl}_{8}(\mathrm{PDC})_{2}(\text { phen })_{4}\right] \cdot \mathbf{2 M e C N}$ (1). The solid-state structure of $\mathbf{1}$ is built from four crystallographically unique bismuth(III) ions, eight chloride ions, four bidentate phen ligands, and two PDC ligands. Bi1 and Bi3 are both seven coordinate, bound to three chloride ions, two nitrogen atoms from one $\kappa^{2}$-phen, and two oxygen atoms from PDC. The Bi1-O distances are 2.5498 (2) and 2.7644(2) $\AA$, the Bi1-Cl distances range from 2.6678(2) to 2.7021(2) $\AA$, and the Bi1-N distances are 2.4538(2) and 2.4806(2) A. In the case of $\mathrm{Bi} 3$; however, the Bi3-O distances are 2.5854(2) and 2.7926(2) $\AA$, the $\mathrm{Bi} 3-\mathrm{Cl}$ distances range from 2.6333(2) to 2.6864(2) $\AA$, and the Bi3-N distances are 2.4424(2) and 2.5008(2) $\AA$. Bi2 and $\mathrm{Bi} 4$ are both six coordinate, bound to one chloride ion, three nitrogen atoms from one $\kappa^{2}$-phen and one PDC, and two oxygen atoms from the PDC. The Bi2-O distances are 2.5609(2) and 2.2869(1) $\AA$ and the Bi2-N distances range from $2.4406(2)$ to $2.5875(2) \AA$. The $\mathrm{Bi} 2-\mathrm{Cl} 4$ distance is $2.4917(2) \AA$, and two long $\mathrm{Bi} \cdots \mathrm{Cl}$ interactions are observed as $3.2081(2)$ and 3.4579(2) $\AA^{63}$ The Bi4-O distances are 2.5633(2) and 2.2811(1) $\AA$, with the Bi4-N distances ranging from 2.4271 (2) to 2.5745 (2) $\AA$. The Bi4-Cl8 distance is 2.4917 (2) $\AA$, and two long $\mathrm{Bi} \cdots \mathrm{Cl}$ interactions are observed as 3.2147(2) and 3.4905 (2) $\AA$. Bi1 and Bi2 are bridged through one oxygen atom (O52) of the carboxylate of the PDC ligand, forming dimeric units. These dimers interact through two chloride atoms ( $\mathrm{Cl} 2$ and $\mathrm{Cl} 3$ ) to form pseudo-tetramers as depicted in Fig. 1. Bi3 and Bi4 are similarly bridged through the carboxylate of one PDC ligand (O62) to form dimeric units that are then further bridged into pseudo-tetramers through relatively long $\mathrm{Bi} \cdot \mathrm{Cl} \cdot \cdots \mathrm{Bi}$ interactions involving two chloride atoms (Cl6 and Cl7). While one outer coordination sphere acetonitrile molecule per formula unit was resolved during the refinement, residual electron density existed outside the cluster. This residual electron density may be attributed to an additional ACN molecule; however, disorder precluded modeling of these atoms, and the model was squeezed to remove the residual electron density. Several intermolecular $\pi-\pi$ interactions are (a)

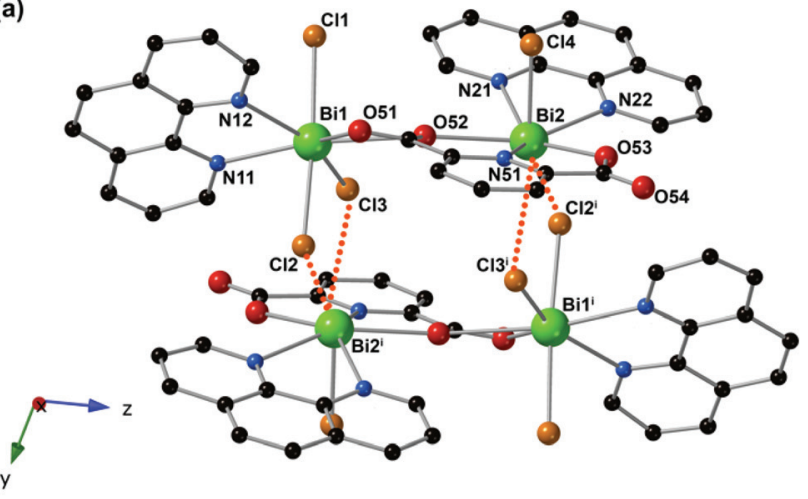

(b)

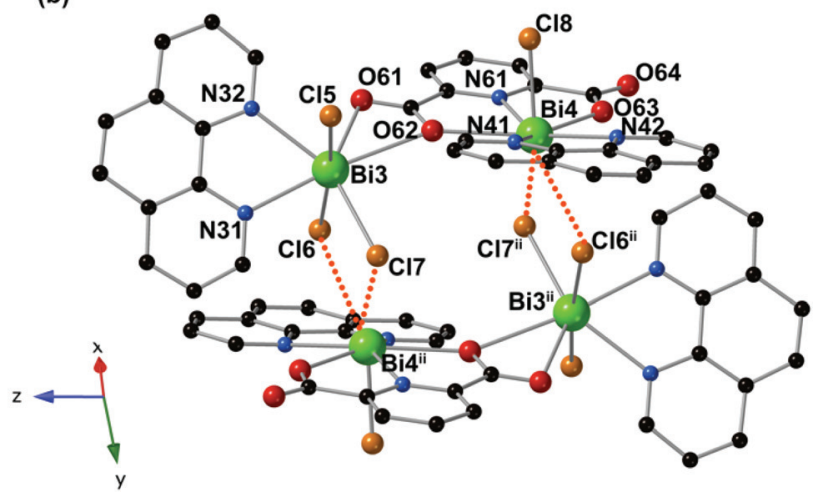

Fig. 1 Illustration of the two unique tetrameric units in 1 which are built from (a) Bi1 and Bi2 and (b) Bi3 and Bi4. Green, red, orange, blue, and black spheres represent bismuth, oxygen, chlorine, nitrogen, and carbon atoms, respectively. Dotted orange lines denote long $\mathrm{Bi} \cdots \mathrm{Cl}$ interactions. Hydrogen atoms and acetonitrile solvent molecules have been omitted for clarity. Symmetry operators: (i) $2-x, 1-y, 1-z$; (ii) $1-x, 1-y,-z$. 
(a)

Z

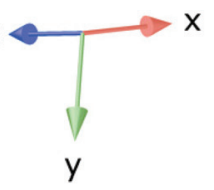

(b)

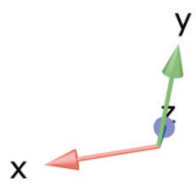

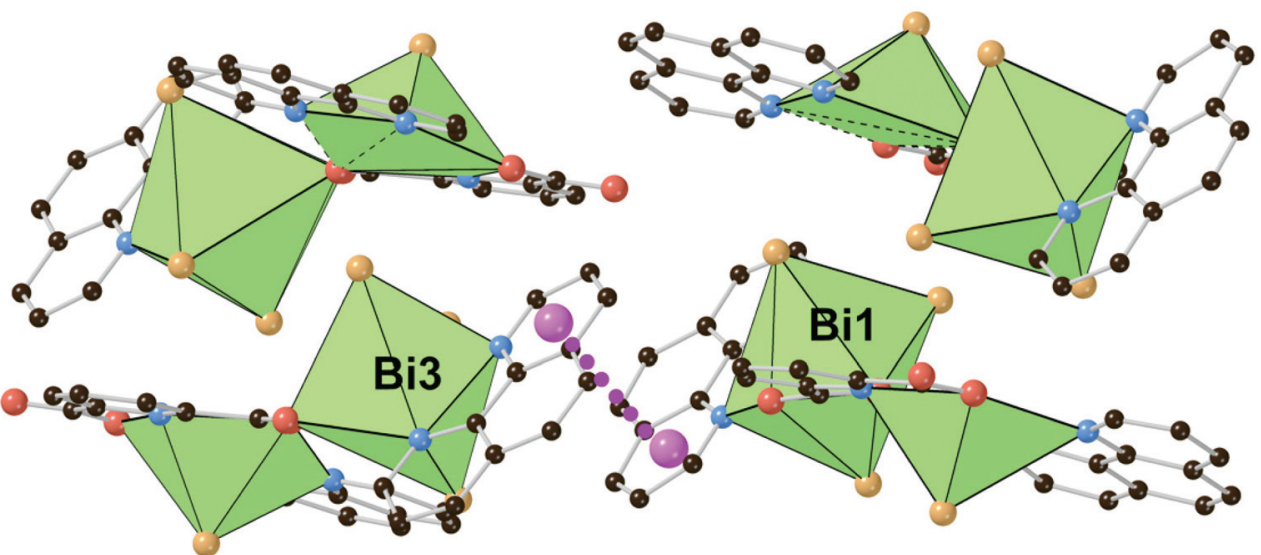

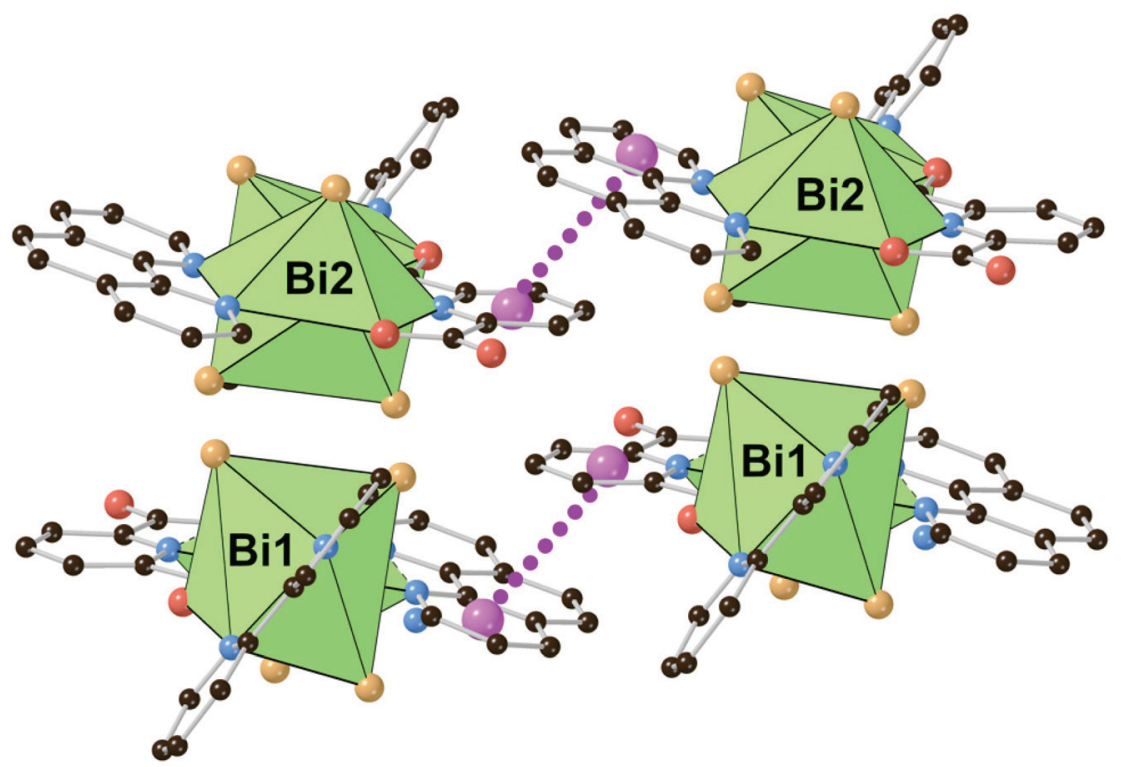

Fig. 2 Polyhedral representation of 1 showing $\pi-\pi$ stacking interactions (purple dashed lines) between (a) two phenanthroline from adjacent Bi1, $\mathrm{Bi} 2$ and Bi3, Bi4 tetramers and (b) phen and PDC from two Bi1, Bi2 tetramers. Green polyhedra, red, orange, blue, and black spheres represent bismuth, oxygen, chlorine, nitrogen, and carbon atoms, respectively. Purple spheres represent ring centroids. Hydrogen atoms and acetonitrile solvent molecules have been omitted for clarity.

observed between the phen and pyridine rings of the pseudotetramers, further stabilizing the crystal structure. As shown in Fig. $2 \mathrm{a}$, moderate $\pi-\pi$ stacking interactions exist between the phen ligands bound to Bi1 and Bi3 (designated as phen1 and phen3, respectively). These interactions were tabulated in Platon $^{47}$ and the strongest interactions exhibit $\mathrm{C}_{\text {phen } 3} \cdots \mathrm{C}_{\text {phen1 }}$ distances of $3.5088(2) \AA$ with a slip angle equal to $18.4^{\circ}$. Weaker interactions exist between the pyridine rings of each PDC ligand and the phen ligands bound to $\mathrm{Bi} 2$ or $\mathrm{Bi} 4$, as depicted in Fig. 2b. For the PDC bound to Bi1 and Bi2 (PDC5) and the phen bound to $\mathrm{Bi} 2$ (phen2), $\mathrm{C}_{\text {phen } 2} \cdots \mathrm{C}_{\mathrm{PDC} 5}$ distances are $3.8167(3) \AA$ with a slip angle of $20.2^{\circ}$. In the case of the $\mathrm{PDC}$ bound to $\mathrm{Bi} 3$ and $\mathrm{Bi} 4$ (PDC6) and the phen bound to $\mathrm{Bi} 4$ (phen4), the $\mathrm{C}_{\text {phen } 4} \cdots \mathrm{C}_{\text {PDC6 }}$ distance is $3.8811(3) \AA$ with a slip angle of $24.6^{\circ}$.
$\left[\mathrm{BiCl}_{3}(\text { phen })_{2}\right]$ (2). As the structure of 2 has been previously reported, only a brief structural description is provided here. Compound $\mathbf{2}$ is built from one crystallographically unique bismuth(III) metal center, three chloride ions, and two bidentate phen ligands. The bismuth ion is seven coordinate, bound to three chloride ions and four nitrogen atoms from the phen ligands (Fig. 3). The Bi-Cl bond distances range from 2.598(1) to $2.748(1) \AA$, and the $\mathrm{Bi}-\mathrm{N}$ distances range from $2.476(2)$ to 2.771(2) ̊. Intermolecular $\pi-\pi$ stacking interactions are observed throughout the structure between adjacent phen rings, with the distance between the centroids $\mathrm{C}_{\mathrm{phen}} \cdots \mathrm{C}_{\text {phen }}$ found to be 3.7557(1) $\AA$ with a slip angle of $22.2^{\circ}$.

$\left[\mathbf{B i}_{2} \mathbf{C l}_{6}(\text { terpy })_{2}\right]$ (3). The structure of $\mathbf{3}$ is built from one crystallographically unique trivalent bismuth ion, one tridentate terpy, and three chloride ions. Each metal center is seven coor- 


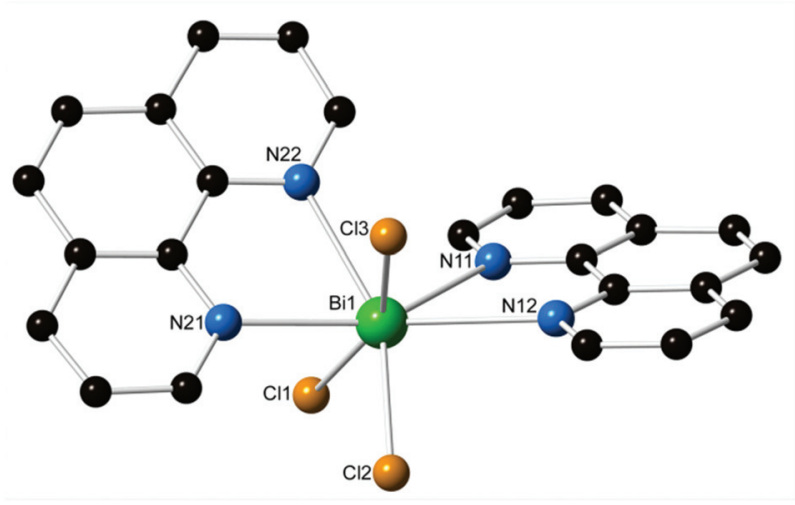

Fig. 3 Illustration of the monomeric unit in 2. Green, orange, blue, and black spheres represent bismuth, chlorine, nitrogen, and carbon atoms, respectively. Hydrogen atoms have been omitted for clarity.

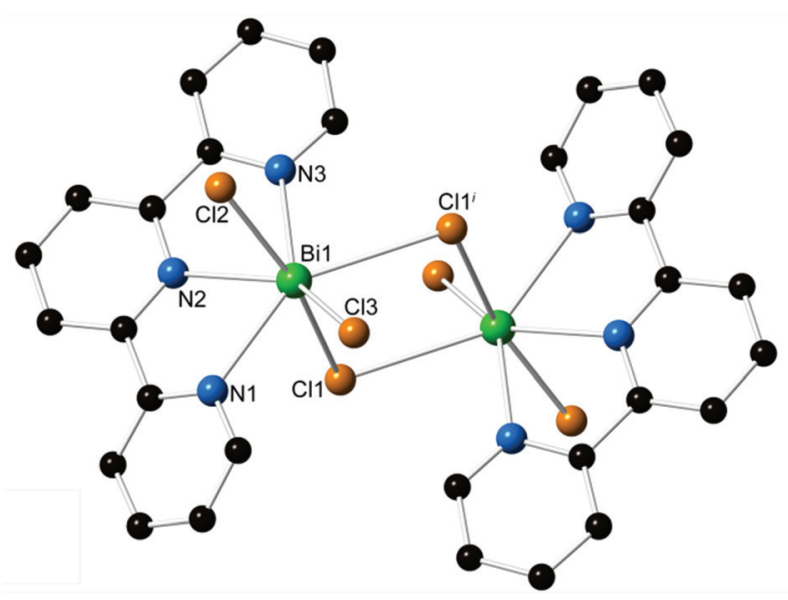

Fig. 4 Illustration of the dimeric units in 3. Green, orange, blue, and black spheres represent bismuth, chlorine, nitrogen, and carbon atoms, respectively. Hydrogen atoms have been omitted for clarity. Symmetry operators: (i) $-x,-y+1,-z+1$.

dinate, adopting a distorted pentagonal bipyramidal coordination geometry, bound to three nitrogen atoms from the terpy ligand and four chloride atoms. The $\mathrm{Bi}-\mathrm{Cl}$ distances range from $2.592(1)$ to $2.814(1) \AA$, while the $\mathrm{Bi}-\mathrm{N}$ bond distances range from $2.479(3)$ to $2.626(3) \AA$. As seen in Fig. 4, bridging chloride atoms, $\mathrm{Cl} 1$ and $\mathrm{Cl}^{\prime}$, link the bismuth metal centers to form discrete molecular dimers. No significant $\pi-\pi$ stacking interactions are present between the terpy rings.

\section{Structural analysis}

More than eighty bismuth-organic compounds containing either bound phen or 2,6-pyridinedicarboxylate have been reported; the majority exist as either discrete monomeric or dimeric units or crystallize as extended networks. Zhang and Feng, for example, synthesized a dimeric bismuth compound containing both 2,6- $\mathrm{H}_{2} \mathrm{PDC}$ and phen, $\left[\mathrm{Bi}_{2}(2,6-\right.$ $\left.\mathrm{PDC})_{2}\left(\mathrm{~N}_{3}\right)_{2}(\text { phen })_{2}\right] \cdot 4 \mathrm{H}_{2} \mathrm{O}$, under ionothermal conditions wherein the bismuth metal centers are bridged through the carboxylate oxygen atoms of the PDC. ${ }^{64}$ To the best of our knowledge, 1 marks the first reported bismuth pseudo-tetramer decorated with phen and/or 2,6-PDC ligands. In the Cambridge Structural Database 2020, reports of discrete chlorobismuth tetramers are limited. Approximately eight chlorobismuth tetramers with organic ligands bound directly to the bismuth metal center have been described. Most of the tetramers reported are polychlorobismuthates, with the general formula $\left[\mathrm{Bi}_{4} \mathrm{Cl}_{x}\right]^{12-x}$ (where $x=16,18$, or 20 ), that are charge balanced by outer coordination sphere metal and/or ligand cations. Dimeric motifs such as that observed in $\mathbf{3}$ are common structural units in bismuth-organic materials literature; however, 3 is the first example of a bismuth-terpy species with chloride in the inner coordination sphere of the metal. Five of the reported bismuth-terpy species contain either bound nitrate or iodine originating from the respective bismuth salt used in the reactions. ${ }^{65-68}$ We have also previously reported a mixed ligand Bi-terpy-thiophenemonocarboxylate compound. ${ }^{37}$ The structural unit of 3 is isostructural to the bromobismuth-phen dimer published by White et al., $\left.\left[\mathrm{Bi}_{2} \mathrm{Br}_{6} \text { (phen }\right)_{4}\right]$, though attempts by the authors to produce the chloride analog were reportedly unsuccessful. ${ }^{42}$ Interestingly, the chlorobismuth dimer is accessible using terpy as a capping ligand, possibly owing to the increased denticity and ability of terpy to better saturate the metal coordination sphere. Furthermore, it is of note that while the structure of 1 exhibits a coordination environment consistent with the presence of a stereochemically active lone pair, as evidenced by the distorted metal coordination geometry, apparent open face, and elongation of $\mathrm{Bi} \cdots \mathrm{Cl}$ interactions, ${ }^{23,26,69}$ little evidence of lone pair activity about the $\mathrm{Bi}$ centers is present in $\mathbf{2}$ and $\mathbf{3}$.

\section{Photoluminescence}

Luminescence spectra for each compound were collected on bulk solid samples at room temperature. The luminescence spectra of the free ligands $\mathrm{H}_{2} \mathrm{PDC}$, phen, and terpy were collected and are reported in the ESI (Fig. S9-S11†). Upon excitation of the free ligands at 343, 363, and $348 \mathrm{~nm}$, respectively, broad emission bands centered between 370-430 nm were observed. Compounds 1-3 exhibit broad visible emission with peaks centered at 570,590, and $537 \mathrm{~nm}$, respectively, as shown in Fig. 5 and 6. A summary of the excitation and emission maxima along with lifetime measurements for the reported compounds is provided in Table 2 . Room temperature timeresolved luminescence studies revealed that $\mathbf{1}$ displayed shortlived luminescence lifetimes with a biexponential decay of $8(1)$ $\mu \mathrm{s}$ and 76(3) $\mu \mathrm{s}$ (Fig. S12 $\dagger$ ). Longer biexponential decays of 14 (1) $\mu$ s and 241(4) for 2 and 10(1) and 196(4) for 3 were observed (Fig. S13 and 14†).

For each compound, the Commission Internationale L'Eclairage (CIE) coordinates were determined from the emission profile and are plotted in Fig. 6. Each compound displays visible yellow-green to orange emission upon exposure to UV light as confirmed by the solid-state luminescence measurements. 
(a)

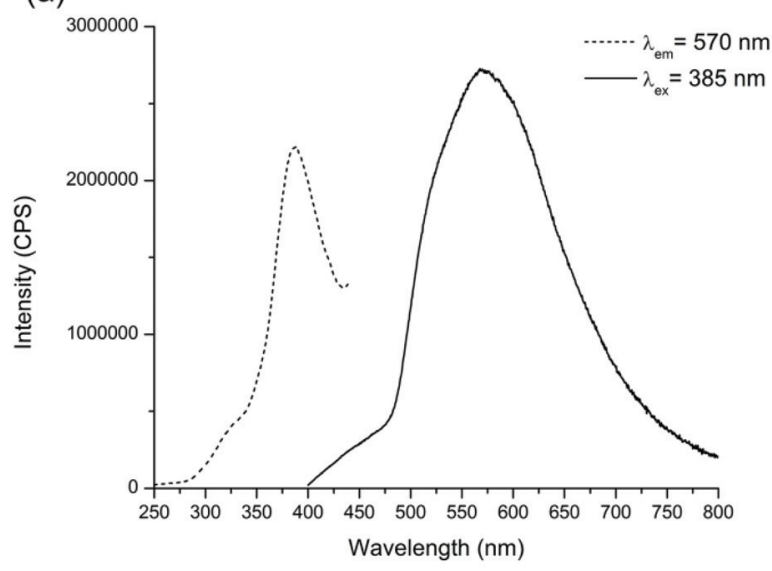

(b)

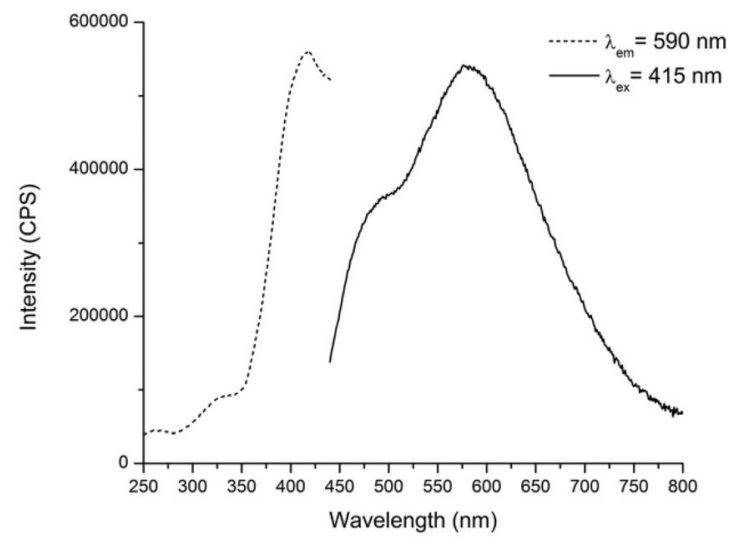

(c)

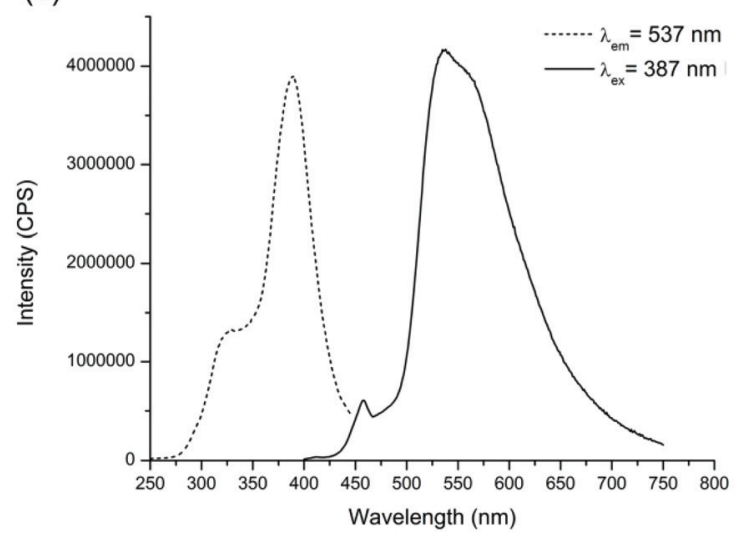

Fig. 5 Room temperature excitation (dashed) and emission (solid) spectra for (a) 1, (b) 2, and (c) 3.

To further our insight into the electronic states and possible transitions correlating to the reported luminescence, quantum mechanical methods have been applied using the ORCA 4.3 software package. ${ }^{48}$ Various cluster cut-outs of each compound were rendered and used as model systems to compute theoretical UV-Vis absorption spectra. These theoretical spectra were compared to the experimentally obtained optical absorption spectra (Fig. S15-S17†). Additionally, molecular orbitals (MOs) involved in the main excitation bands of

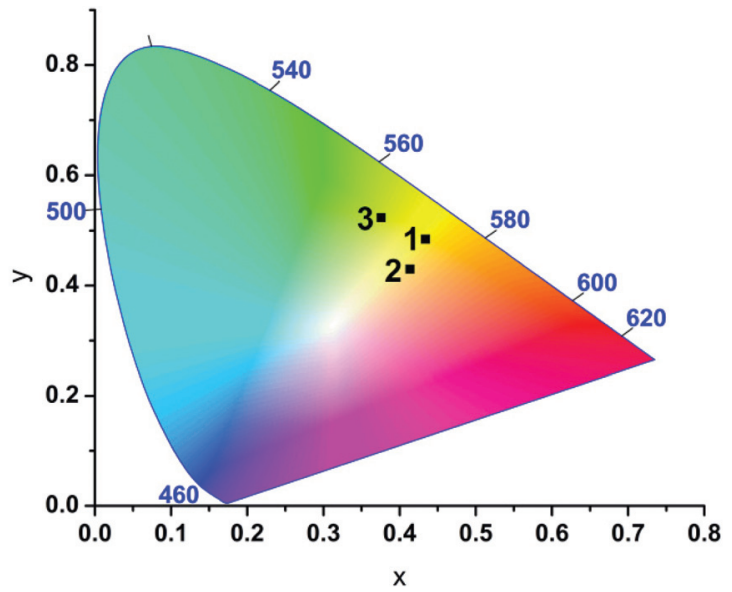

Fig. 6 Room temperature CIE chromaticity coordinates for 1-3.

Table 2 Photophysical measurements for 1-3

\begin{tabular}{llll}
\hline & $\begin{array}{l}\text { Maximum } \\
\text { excitation }(\mathrm{nm})\end{array}$ & $\begin{array}{l}\text { Maximum } \\
\text { emission }(\mathrm{nm})\end{array}$ & $\begin{array}{l}\text { Lifetime } \\
(\mu \mathrm{s})\end{array}$ \\
\hline 1 & 385 & 570 & $8(1), 76(3)$ \\
2 & 415 & 590 & $14(1), 241(4)$ \\
3 & 387 & 537 & $10(1), 196(4)$ \\
\hline
\end{tabular}

the absorption spectra were calculated for each compound. While there is a degree of uncertainty in the calculated transition wavelengths and oscillator strengths, the combined theoretical and experimental data have provided insight into the transitions responsible for the emissive behavior of the compounds.

For 1, several cluster cut-outs were prepared and used for subsequent calculations, including the as-reported pseudo-tetramer, $\left[\mathrm{Bi}_{4} \mathrm{Cl}_{8}(\mathrm{PDC})_{2}(\text { phen })_{4}\right]$, and several dimers of tetramers, $\left[\mathrm{Bi}_{4} \mathrm{Cl}_{8}(\mathrm{PDC})_{2}(\text { phen })_{4}\right]_{2}$. Looking at the general shape of the spectra (Fig. 7), the different renderings of the pseudo-tetramers do not exhibit fundamental differences. Table 3 lists the position of the lowest states for each "dimer" of tetramers, showing that the lowest part could be split into two regions separated by a frontier at $390 \mathrm{~nm}$. For simplicity, our analysis focused on the strong absorption peaks located at $350 \mathrm{~nm}$ and $\sim 400 \mathrm{~nm}$ of one of the tetramer cut-outs (C). Decomposition of the peaks is reported in Table 4 and the MOs involved in the absorption process are depicted in Fig. 8.

The lower energy bands involve excitation from the bismuth-chloride subunit to the phen groups (HOMO-1 $\rightarrow$ LUMO+2) in a "metal"-to-ligand charge transfer (Fig. 8). Different than typical MLCT, there is strong mixing between the chloride orbitals and that of the $\mathrm{Bi}^{3+}$ ion; thus, the likely excited state involved in the CT process does not exclusively have metal character but involves the whole $\mathrm{BiCl}_{3}$ subunit. Upon de-excitation, these transitions should correspond to a ligand-to-metal subunit charge transfer (LMCT). Interestingly, the calculations show that the PDC ligand does not appear to 


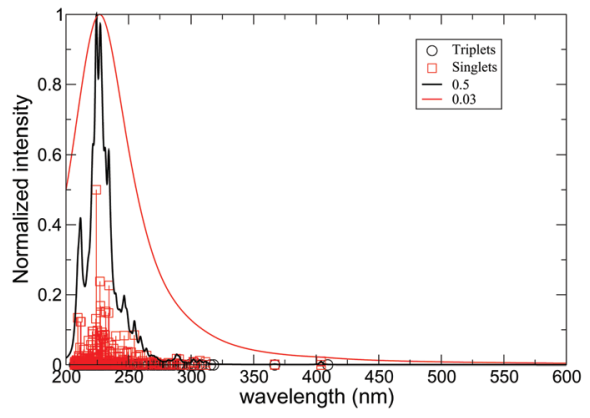

(a) 1 monomer

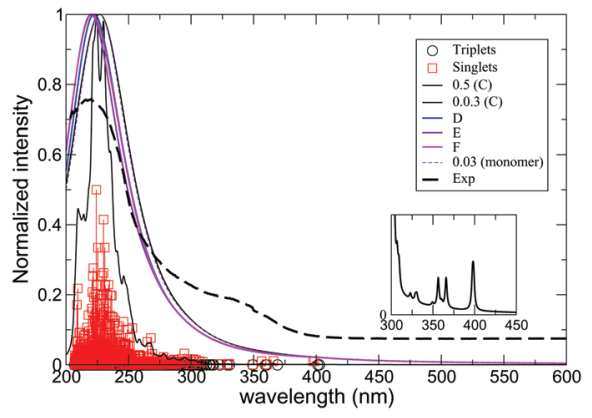

(b) 1 dimer

Fig. 7 (a) Computed UV-vis absorption spectrum of 1 with two different Gaussian heights (black and red solid lines) calculated with one tetramer. (b) Computed UV-vis absorption spectrum of 1 calculated with two tetramers in various orientations (C, D, E, \& F) overlaid with the experimental absorption spectrum (black dashed line). The lower part of the theoretical spectrum is reported in the box (squares represent the position of all the states in that specific region).

Table 3 Lowest absorption wavelengths of singlet states (nm) of various renderings (C, D, E, F) of "dimers" of tetramers for 1

\begin{tabular}{llll}
\hline$\lambda_{\mathrm{C}}(\mathrm{nm})$ & $\lambda_{\mathrm{D}}(\mathrm{nm})$ & $\lambda_{\mathrm{E}}(\mathrm{nm})$ & $\lambda_{\mathrm{F}}(\mathrm{nm})$ \\
\hline 398.4 & 406.2 & 403.2 & 398.4 \\
397.2 & 406.2 & 403.2 & 398.3 \\
- & 393.6 & 401.2 & 386.4 \\
- & 393.5 & 401.2 & 386.4 \\
366.2 & - & - & - \\
360.7 & - & - & - \\
356.6 & 368.2 & 365.5 & 350.6 \\
349.6 & 368.2 & 365.5 & 350.6 \\
330.4 & 357.4 & 363.3 & 341.1 \\
329.1 & 357.4 & 363.3 & 341.1 \\
322.9 & 314.3 & 309.2 & 308.5
\end{tabular}

Table 4 Decomposition of the main singlet to singlet excitations of 1

$\lambda$

(nm) Decomposition of the main singlet to singlet excitations

\begin{tabular}{ll}
\hline 398.4 & $-0.99(\mathrm{HOMO}-1 \rightarrow$ LUMO+2) \\
397.2 & $-0.77(\mathrm{HOMO}-1 \rightarrow$ LUMO+2) $-0.63(\mathrm{HOMO} \rightarrow$ LUMO+1) \\
366.2 & $0.98(\mathrm{HOMO}-3 \rightarrow$ LUMO +1$)-0.11(\mathrm{HOMO}-2 \rightarrow$ LUMO+8) \\
360.7 & $-0.99(\mathrm{HOMO}-2 \rightarrow$ LUMO+6) \\
356.6 & $0.60(\mathrm{HOMO} \rightarrow$ LUMO+8) $-0.48(\mathrm{HOMO}-1 \rightarrow$ LUMO+8) 0.40 \\
& $($ HOMO $\rightarrow$ LUMO+3) \\
349.6 & $-0.76(\mathrm{HOMO} \rightarrow$ LUMO+6) $-0.63(\mathrm{HOMO} \rightarrow$ LUMO+8)
\end{tabular}

be involved in CT at lower energies. However, higher energy absorption bands can be attributed to ligand-to-ligand charge transfer between the ligands, resulting in underlying ligand emissions which are supported by experimentally observed biexponential decay. To further explore the absorption, the calculated spectra (solid lines) were compared to the experimental absorption spectrum (black dashed line) (Fig. 7b). The intensity of the simulated spectrum was scaled for easier comparison. From the overlay, the general shape of the theoretical spectrum is in reasonable agreement with the experimental data. Moreover, in the lower part of the spectra, the more intense singlet to singlet excitations are about $395 \mathrm{~nm}$, a value that matches the $385 \mathrm{~nm}$ excitation wavelength used for the experimental characterization of the compound.

For the neutral monomer in 2, three cluster sizes were prepared including the as-reported monomer, $\left[\mathrm{BiCl}_{3}\right.$ phen 2$]$, a pseudo-trimer built from three monomeric units, $\left[\mathrm{BiCl}_{3} \mathrm{phen}_{2}\right]_{3}$, and a pseudo-tetramer built from four monomeric units, $\left[\mathrm{BiCl}_{3} \text { phen }\right]_{4}$. When looking at the electron distribution of the electronic ground state, it is worth noting that the $\mathrm{BiCl}_{3}$ subunit tends to strongly attract the electrons from the two donor groups, though predominately from the one with the shortest $\mathrm{Bi}-\mathrm{N}$ distances. The Mulliken population analysis yields a total charge on the bismuth center of $1.5 e^{-}$, indicating some degree of covalency between bismuth and the phen groups. The deformation density shown in Fig. 9 nicely supports the fact that there is an accumulation of density on the $\mathrm{BiCl}_{3}$ subunit (blue regions), along with a depletion in the $\mathrm{N}$-donor ligands.

An important aspect that can be examined using quantum mechanical calculations is the qualitative evolution of the absorption spectra as a function of aggregate size. The absorption spectra at the SF level (Fig. 10) describe the effect of the Lorentzian width used to convolute the spectrum. The cluster aggregate size effects are illustrated in Fig. 10b. As shown in Fig. 10b, the main absorption bands above $350 \mathrm{~nm}$ are slightly affected by the size of the aggregate, going from the monomer (Fig. 10a) to the trimer (Fig. 10b), and the relative intensities of the two main bands evolve with respect to the size of the system. For example, the band at $\sim 450 \mathrm{~nm}$ for the monomer is blue-shifted to $425 \mathrm{~nm}$ for the larger, linear trimer (Fig. 10b). The larger compound (tetramer) made of four subunits has a very similar spectrum (Fig. 10c) to that of the trimer (Fig. 10b).

The decomposition of the low-lying states is proposed in Table $\mathrm{S} 1 \dagger$ and the MOs are represented in Fig. S25 and S26† for the trimeric and tetrameric units, respectively. In the larger aggregates, the lowest energy bands (i.e. above $400 \mathrm{~nm}$ ) correspond to excitation out of $\mathrm{BiCl}_{3}$ centered orbitals to the $\pi^{*}$ orbitals of the closest phen group (HOMO-2 $\rightarrow$ LUMO in the linear trimer; HOMO-1 $\rightarrow$ LUMO+5, LUMO+6, and LUMO+7 in the tetramer). The other bands (below $400 \mathrm{~nm}$ ) are a combi- 


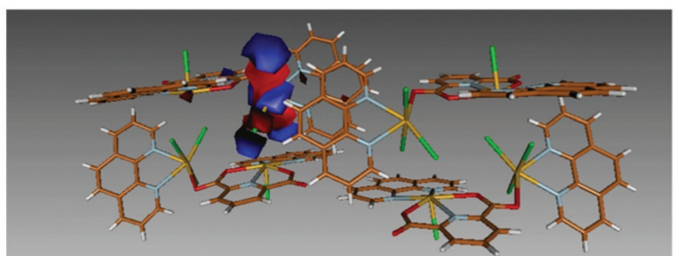

HOMO -3

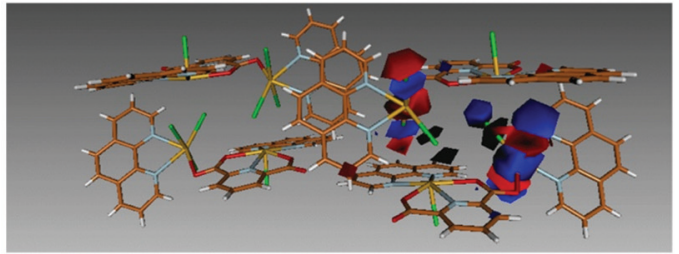

HOMO -1

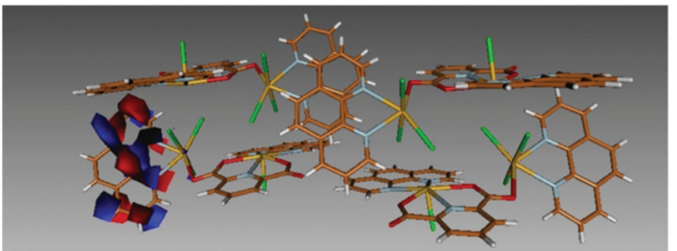

LUMO

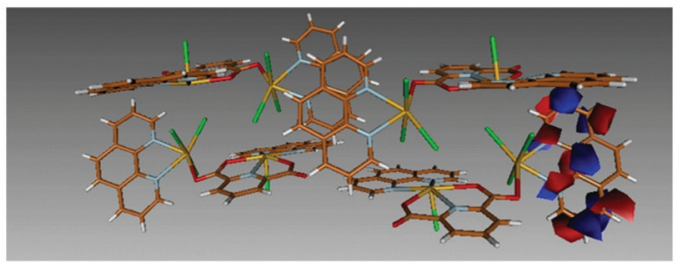

$\mathrm{LUMO}+2$

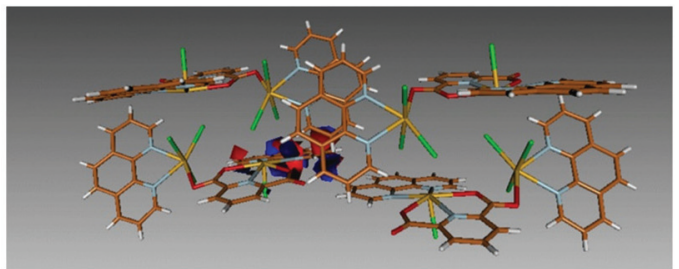

$\mathrm{LUMO}+6$

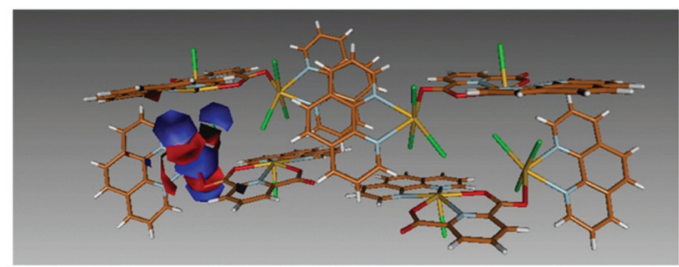

HOMO -2

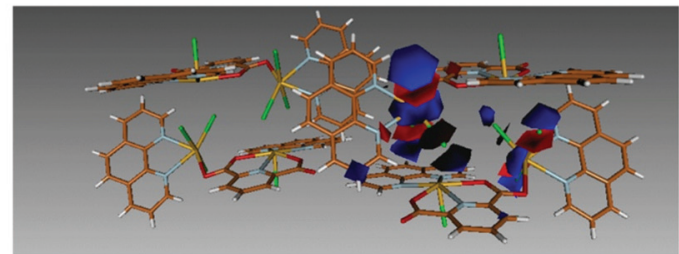

HOMO

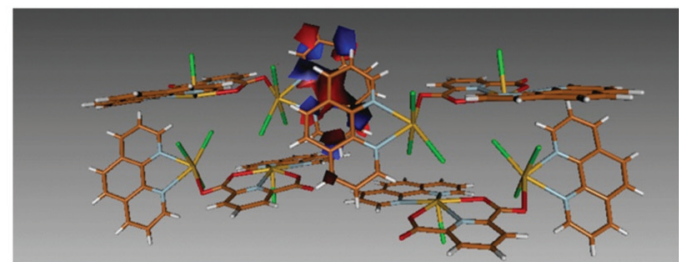

$\mathrm{LUMO}+1$

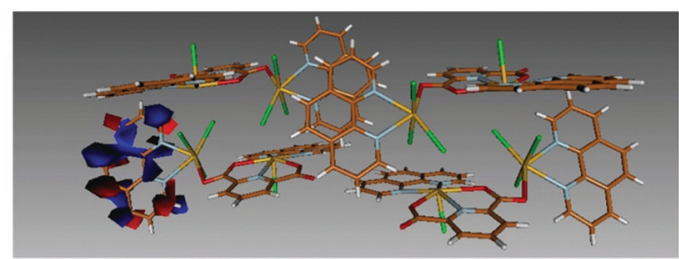

$\mathrm{LUMO}+3$

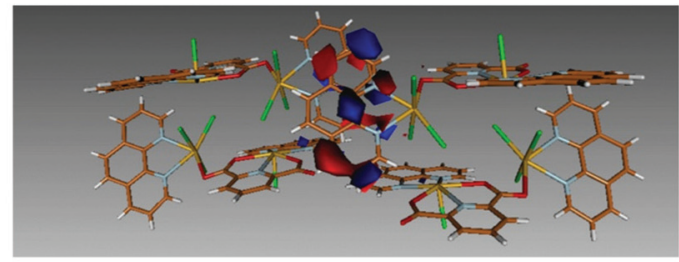

$\mathrm{LUMO}+8$

Fig. 8 Molecular orbitals implied in the main low-lying excitations of 1. Note that the cut-out shown is for a "dimer" of tetramers.

nation of MLCT as expected for such types of compounds, and are in agreement with the recent work by Sorg et al. ${ }^{17}$ or Ouerghi et al. ${ }^{70}$ Interestingly, the experimentally determined excitation wavelength used to collect the emission spectra is $415 \mathrm{~nm}$, which agrees well with the lowest absorption energy predicted with the highest intensity in the low part of the spectrum (Fig. 10b) for a singlet to singlet excitation.

For 3, four cluster cut-outs were rendered: (i) the dimeric unit, $\left.\left[\mathrm{Bi}_{2} \mathrm{Cl}_{6} \text { (terpy) }\right)_{2}\right]$, two different dimer of dimers (ii) $\left[\mathrm{Bi}_{2} \mathrm{Cl}_{6}(\text { terpy })_{2}\right]_{2}$ with the ligands perpendicular to each other (ortho) and (iii) $\left.\left[\mathrm{Bi}_{2} \mathrm{Cl}_{6} \text { (terpy) }\right]_{2}\right]_{2}$ with the dimers in parallel to each other (in plane), and (iv) a tetramer of dimers, $\left.\left[\mathrm{Bi}_{2} \mathrm{Cl}_{6} \text { (terpy) }\right]_{4}\right]_{4}$. As shown in Fig. 11, many bands are common between the considered systems. The region over 350-450 nm exhibits a dense absorption band. When going from the dis- crete dimer to larger cut-outs, an increase in the number of states is observed which is expected from larger aggregates. However, the main features of the spectra do not change substantially. In the lower energy part of the spectrum of the tetrameric unit, for example, there are three bands with relatively strong oscillator strength above $380 \mathrm{~nm}$ (see Table S2; $\uparrow$ MOs are shown in Fig. 12). The peak at $411 \mathrm{~nm}$ can be attributed to the excitation of the $\mathrm{BiCl}_{3}$ subunit to nonbonding orbitals of the closest terpy groups belonging to the same molecular subsystem (HOMO-6 $\rightarrow$ LUMO+6, see Fig. 12). The two other lower wavelength absorption bands are more delocalized as the main contribution to the transition corresponds to an excitation of an electron localized on the $\mathrm{BiCl}_{3}$ center to an orbital of the "opposite" terpyridine ligand (HOMO-15 $\rightarrow$ LUMO+1 and HOMO-14 $\rightarrow$ LUMO+2; Fig. 12). Based on the theoretical 


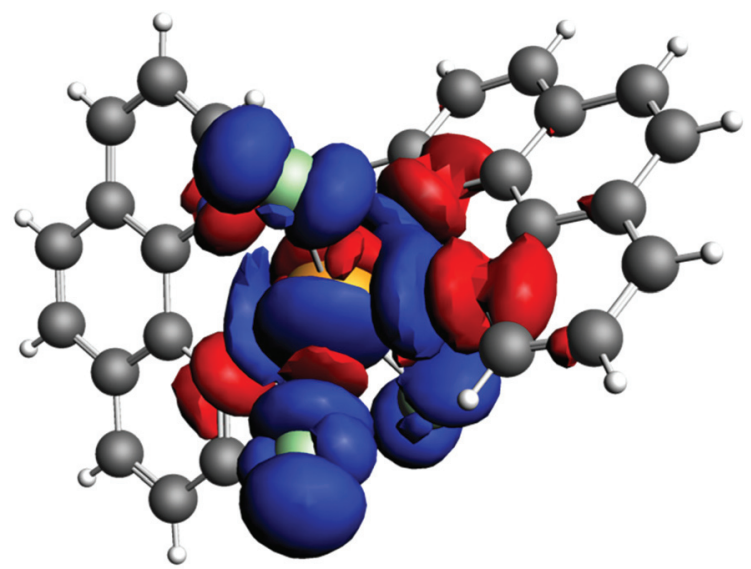

Fig. 9 Deformation density of 2 . The red areas correspond to a depletion of the density as compared to the isolated fragments $\left(\mathrm{BiCl}_{3}\right.$ and the two phenanthroline ligands), while the blue regions correspond to accumulation of electron density.

spectrum one would expect that three bands centered at 387 , 395 , and $411 \mathrm{~nm}$ may be used to probe the luminescence of the compounds; the optimal excitation wavelength determined experimentally was $387 \mathrm{~nm}$.
Yet, agreement between the experimental absorption data and the simulation is rather poor, as shown in Fig. 11c. Two clear absorption bands are observed experimentally, located at 240 and $370 \mathrm{~nm}$, with none above $400 \mathrm{~nm}$, while the simulated data propose one main band at 240 and $275 \mathrm{~nm}$ and a second dense, but less intense region up to $430 \mathrm{~nm}$. Regarding the two previous cases and the existing coherence, no reasonable explanation for such a disagreement has yet been identified.

Our theoretical analysis compares well with other luminescent polychlorobismuth-organic compounds including the chlorobismuth-4,4'-bipyridine coordination polymers reported by Sorg et al. ${ }^{17}$ Computational studies identified MLCT, originating from the occupied orbitals of the bismuth chloride subunit (in their case, $\mathrm{Bi}_{2} \mathrm{Cl}_{6}$ ) to ligand orbitals delocalized over several ligands, as being responsible for the excitation bands and subsequent emission resulting from the corresponding LMCT.

\section{Thermal stability}

The thermal stabilities of compounds $\mathbf{1}$ and $\mathbf{3}$ were investigated using thermogravimetric analysis under flowing air (Fig. S18 and S19†). For 1, the total weight loss was 56.1\% and

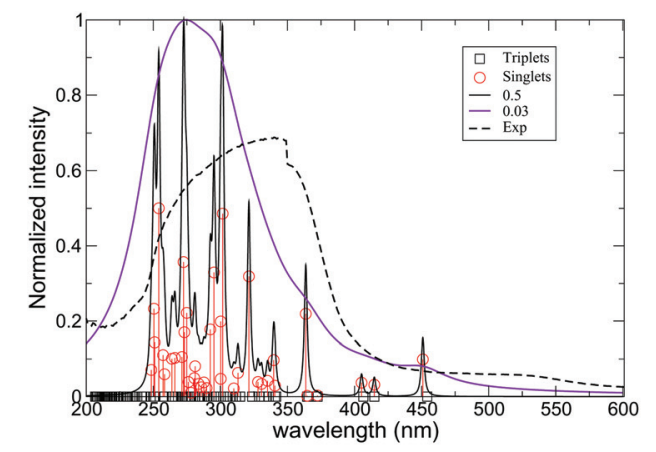

(a) 2 monomer

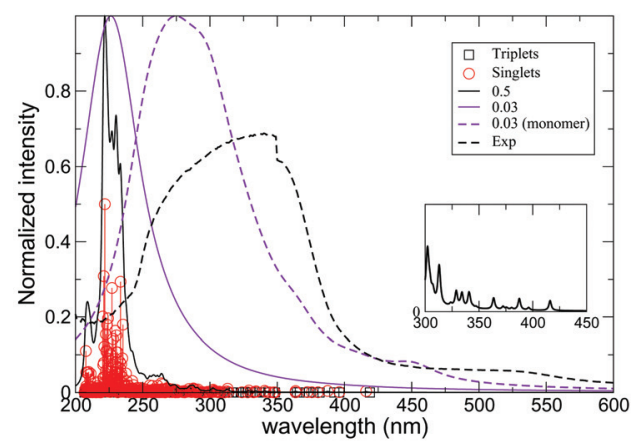

(b) 2 trimer

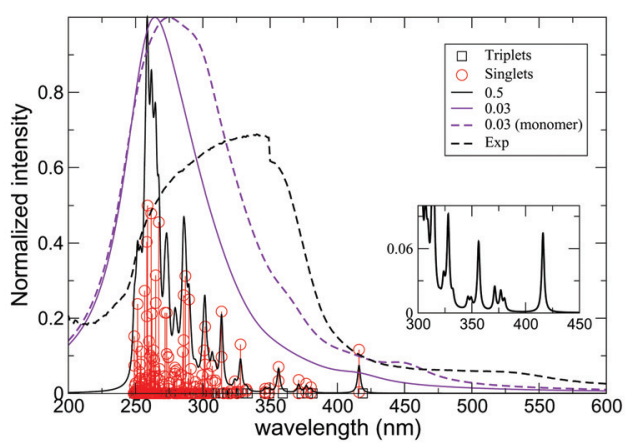

(c) 2 tetramer

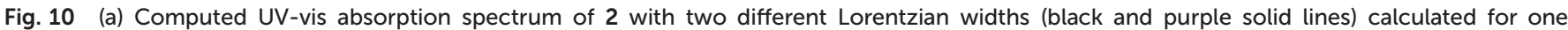

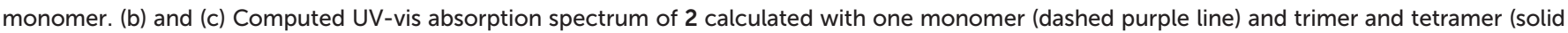

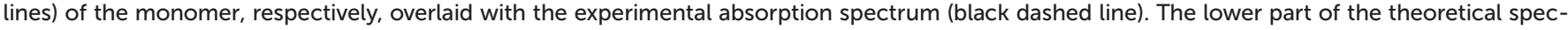
trum is reported in the inset (squares represent the position of all the states in that specific region). 


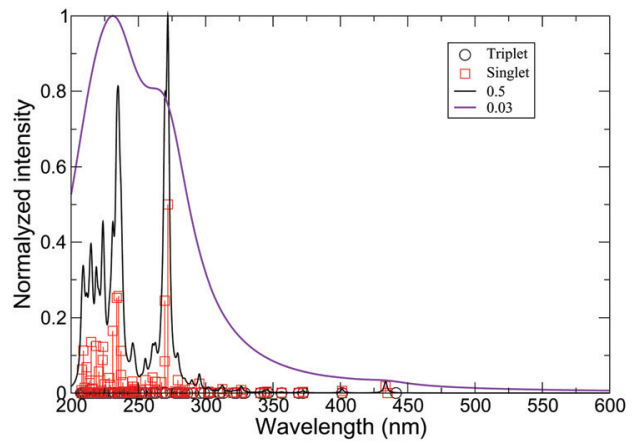

(a) 3 monomer

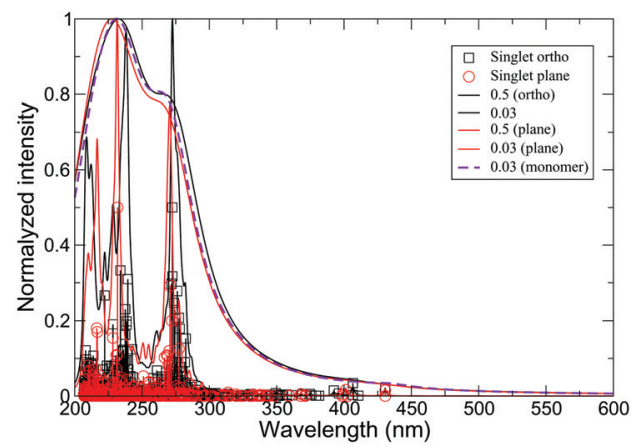

(b) 3 dimer

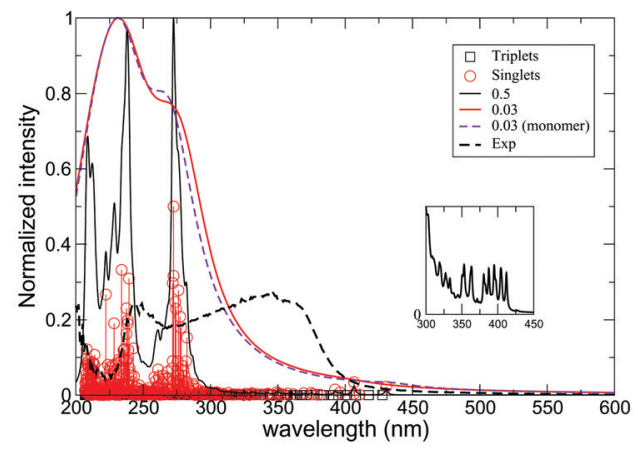

(c) 3 tetramer

Fig. 11 (a) Computed UV-vis absorption spectrum of 3 with two different Lorentzian (black purple solid lines) calculated with one monomer of dimer. (b) Computed UV-vis absorption spectrum of 3 calculated with one dimer (dashed purple line) and two dimers of dimer (solid lines) in two different orientations. (c) Computed UV-vis absorption spectrum of 3 calculated with one dimer (dashed purple line) and a tetramer of dimers (solid red line) overlaid with the experimental absorption spectrum (black dashed line). The lower part of the theoretical spectrum is reported in the box (squares represent the position of all the states in that specific region).

occurred over four consecutive steps. The first weight loss of roughly $13 \%$ occurred over $200-275{ }^{\circ} \mathrm{C}$ and is consistent with the loss of two MeCN and one phen. The second weight loss of $25.9 \%$ was complete by $350{ }^{\circ} \mathrm{C}$, and the third weight loss $(4.8 \%)$ was complete by $425{ }^{\circ} \mathrm{C}$. Attribution of these steps is somewhat ambiguous, but the combined weight losses are consistent with decomposition of two phen groups and two PDC units. The final weight loss of $12.1 \%$ was complete by $600{ }^{\circ} \mathrm{C}$ and is consistent with the loss of one phen unit and three chloride ions (or alternatively seven $\mathrm{Cl}$ ). For 3 , the total weight loss was $67.3 \%$ and occurred over two consecutive steps. The first weight loss of $23.5 \%$ occurred over $180{ }^{\circ} \mathrm{C}$ to $\sim 300{ }^{\circ} \mathrm{C}$, and the second weight loss of $43.8 \%$ was complete by $360{ }^{\circ} \mathrm{C}$. Assignment of these steps remains unclear; however, in an effort to identify the thermal decomposition products, powder X-ray diffraction data was collected on the resulting powders. The PXRD pattern of the thermal decomposition product of 1 did not index to any known bismuth oxide, bismuth chloride, or bismuth oxychloride phase (Fig. S20†). However, the PXRD pattern of the thermal decomposition product of 3 appears to consist of some mixture of BiOCl (calc. 52.5\%) and $\mathrm{Bi}_{24} \mathrm{O}_{31} \mathrm{Cl}_{10}$ (calc. 55.5\%) (Fig. S21†). As the total weight loss for $\mathbf{3}$ was greater than what could be accounted for as decomposition to either BiOCl or $\mathrm{Bi}_{24} \mathrm{O}_{31} \mathrm{Cl}_{10}$, the onset of $\mathrm{BiCl}_{3}$ sublimation above $300{ }^{\circ} \mathrm{C}$ formed in situ may account for this discrepancy. ${ }^{16}$

\section{Raman spectroscopy}

Raman spectra were collected for $\mathbf{1}$ and $\mathbf{3}$ on solid samples of the bulk phases at room temperature (Fig. S22 and S23 lower wavenumbers, the peak around $245 \mathrm{~cm}^{-1}$ in each spectrum can be attributed to a $\nu(\mathrm{Bi}-\mathrm{Cl})$ vibration. Peaks for $\mathbf{1}$ and 3 in the range of $c a .1000$ to $1570 \mathrm{~cm}^{-1}$ may be attributed to absorptions from the phen/PDC and terpy ligands, respectively. ${ }^{64,71}$

\section{Conclusions}

Three luminescent bismuth(III)-organic compounds bearing $\mathrm{N}$-donor ligands were synthesized and structurally characterized. The spectroscopic properties of the compounds were also examined. The compounds varied in nuclearity, ranging from monomeric units capped by phenanthroline (2) to a dimeric 


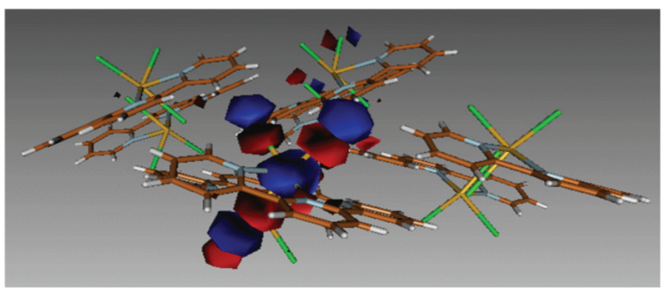

HOMO -15

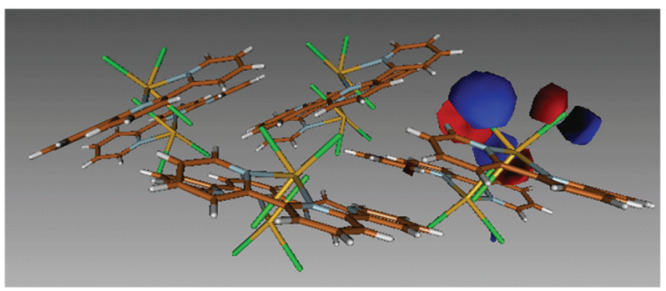

HOMO -13

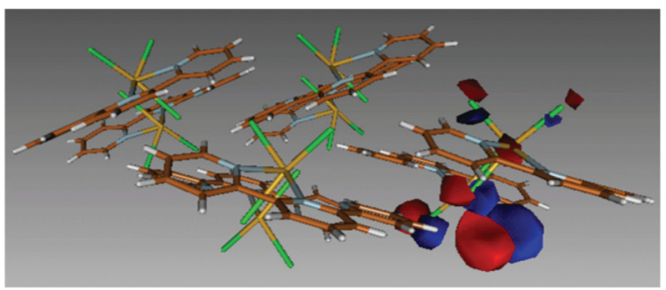

HOMO - 10

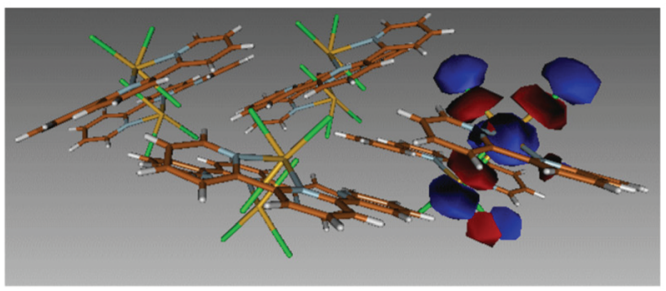

HOMO -6

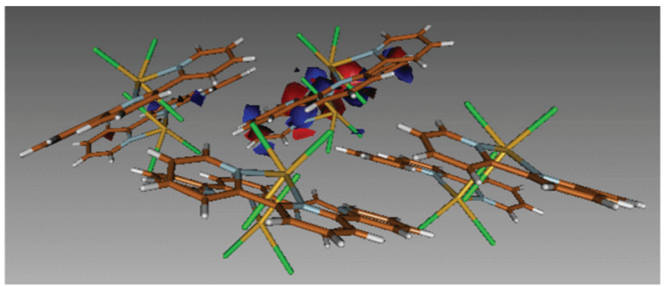

LUMO +2

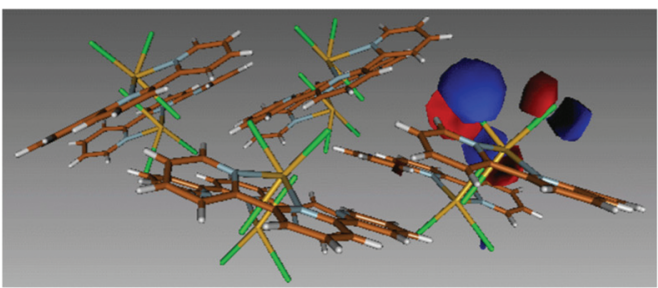

HOMO -14

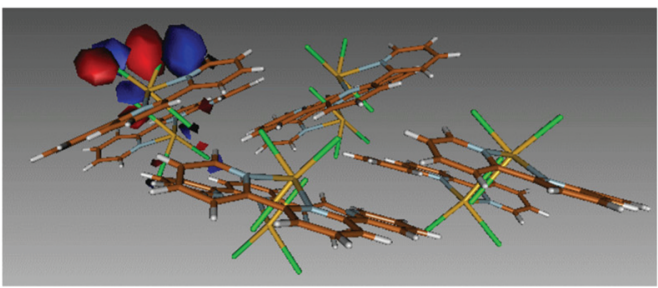

HOMO -11

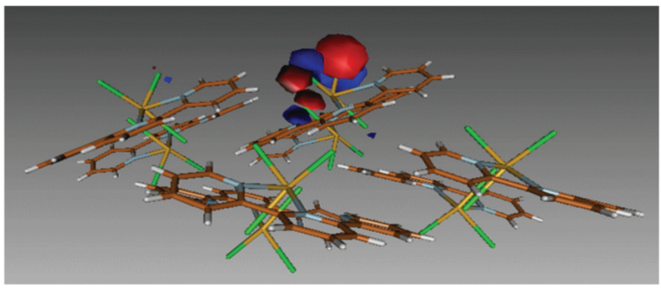

HOMO -9

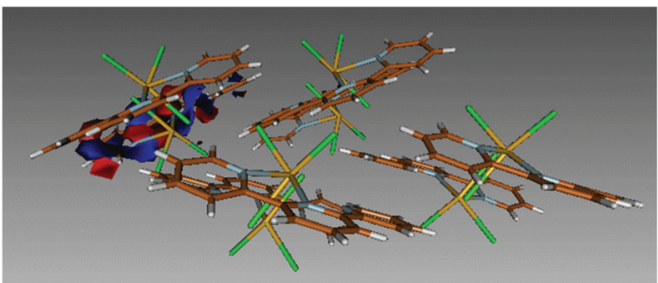

LUMO +1

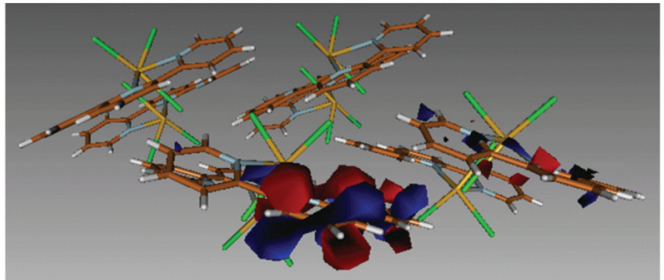

LUMO +4

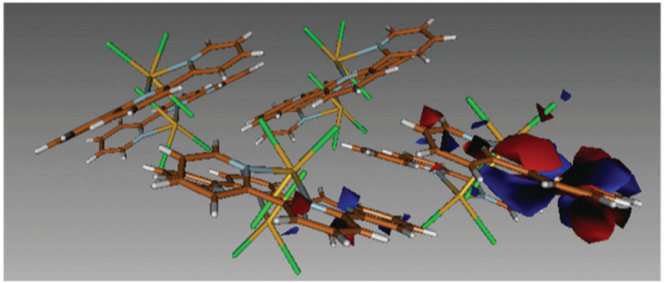

LUMO +6

Fig. 12 Molecular orbitals implied in the main first excitations of 3 for the tetrameric unit.

species capped by terpyridine (3) to a novel pseudo-tetrameric complex bearing both 2,6-PDC and phenanthroline (1). The compounds exhibited visible emission ranging from orange to yellow-green upon UV exposure. Computational analyses aimed at elucidating the emissive pathways were performed and based on these studies the observed luminescence behavior are primarily attributed to ligand-to-ligand and ligand-tometal charge transfer transitions. 


\section{Author contributions}

The manuscript was written through contributions of all authors. All authors have given approval to the final version of the manuscript.

\section{Conflicts of interest}

There are no conflicts to declare.

\section{Acknowledgements}

The authors gratefully acknowledge the Clare Booth Luce Foundation for their support. The authors would also like to thank the National Science Foundation for acquisition of the single crystal X-ray diffractometer (NSF CHE-1337975) and the Raman spectrometer (NSF CHE-1429079). RLA acknowledges the DoD-SMART Scholarship Program for funding. FR and VV acknowledge support by the French Government through the Program "Investissement d'avenir" (LABEX CaPPA/ANR-11-LABX-0005-01 and I-SITE ULNE/ANR-16IDEX-0004 ULNE), as well as by the Ministry of Higher Education and Research, Hauts de France Council and European Regional Development Fund (ERDF) through the Contrat de Projets état-Région (CPER -CLIMIBIO). Furthermore, this work was granted access to the HPC resources of [CINES/IDRIS/TGCC] under the allocation 2019-2020 [A0050801859] made by GENCI.

\section{References}

1 M. Mehring, From molecules to bismuth oxide-based materials: Potential homo- and heterometallic precursors and model compounds, Coord. Chem. Rev., 2007, 251(7-8), 974-1006.

2 G. G. Briand and N. Burford, Bismuth compounds and preparations with biological or medicinal relevance, Chem. Rev., 1999, 99(9), 2601-2657.

3 N. Yang and H. Sun, Biocoordination chemistry of bismuth: Recent advances, Coord. Chem. Rev., 2007, 251(17-20), 2354-2366.

4 S. Roggan, C. Limberg, M. Brandt and B. Ziemer, Organometallic Mo-O-Bi complexes, J. Organomet. Chem., 2005, 690(23), 5282-5289.

5 V. Stavila, R. L. Davidovich, A. Gulea and K. H. Whitmire, Bismuth(III) complexes with aminopolycarboxylate and polyaminopolycarboxylate ligands: Chemistry and structure, Coord. Chem. Rev., 2006, 250(21-22), 2782-2810.

6 C. Liao, Z. Ma, G. Dong and J. Qiu, BiOI nanosheets decorated TiO2 nanofiber: Tailoring water purification performance of photocatalyst in structural and photo-responsivity aspects, Appl. Surf. Sci., 2014, 314, 481-489.

7 L. Zhang, J. Yang, X. Y. Zhao, X. Xiao, F. Q. Sun, X. X. Zuo and J. M. Nan, Small-molecule surface-modified bismuth- based semiconductors as a new class of visible-light-driven photocatalytic materials: Structure-dependent photocatalytic properties and photosensitization mechanism, Chem. Eng. J., 2020, 380, 12.

8 U.S. Geological Survey, Bismuth, U.S. Department of the Interior, 2019, pp. 34-35.

9 P. J. Sadler, H. Li and H. Sun, Coordination chemistry of metals in medicine: target sites for bismuth, Coord. Chem. Rev., 1999, 185-186(0), 689-709.

10 D. Keogan and D. Griffith, Current and Potential Applications of Bismuth-Based Drugs, Molecules, 2014, 19(9), 15258.

$11 \mathrm{X}$. Meng and Z. Zhang, Bismuth-based photocatalytic semiconductors: Introduction, challenges and possible approaches, J. Mol. Catal. A: Chem., 2016, 423, 533549.

12 N. Shen, J. Li, Z. Wu, B. Hu, C. Cheng, Z. Wang, L. Gong and X. Huang, $\alpha-$ and $\beta-[\operatorname{Bmim}]\left[\operatorname{BiCl} 4\left(2,2^{\prime}-\mathrm{bpy}\right)\right]$ : Two Polymorphic Bismuth-Containing Ionic Liquids with Crystallization-Induced Phosphorescence, Chem. - Eur. J., 2017, 23(62), 15795-15804.

13 A. C. Wibowo, S. A. Vaughn, M. D. Smith and H.-C. zur Loye, Novel Bismuth and Lead Coordination Polymers Synthesized with Pyridine-2,5-Dicarboxylates: Two Single Component "White" Light Emitting Phosphors, Inorg. Chem., 2010, 49(23), 11001-11008.

14 A. C. Wibowo, M. D. Smith and H.-C. zur Loye, Structural Diversity of Metal-Organic Materials Containing Bismuth (III) and Pyridine-2,5-Dicarboxylate, Cryst. Growth Des., 2011, 11(10), 4449-4457.

15 A. C. Wibowo, M. D. Smith and H. C. zur Loye, A new Kagome lattice coordination polymer based on bismuth and pyridine-2,5-dicarboxylate: structure and photoluminescent properties, Chem. Commun., 2011, 47(26), 73717373.

16 J. Heine, T. Wehner, R. Bertermann, A. Steffen and K. Müller-Buschbaum, (2)(infinity) $\mathrm{Bi}_{2} \mathrm{Cl}_{6}(\mathrm{pyz})_{(4)}$ : A 2D-Pyrazine Coordination Polymer As Soft Host Lattice for the Luminescence of the Lanthanide Ions $\mathrm{Sm}^{3+}, \mathrm{Eu}^{3+}, \mathrm{Tb}^{3+}$, and $\mathrm{Dy}^{3+}$, Inorg. Chem., 2014, 53(14), 7197-7203.

17 J. R. Sorg, T. Wehner, P. Matthes, R. Sure, S. Grimme, J. Heine and K. Müller-Buschbaum, Bismuth as Versatile Cation for Luminescence in Coordination Polymers from BiX3/4,4'-bipy: Understanding of Photophysics by Quantum Chemical Calculations and Structural Parallels to Lanthanides, Dalton Trans., 2018, 47, 7669-7681.

18 X. P. Zhang, H. R. Tian, G. F. Yan, Y. Su, Y. L. Feng and J. W. Cheng, Incorporating different secondary building units of $\{\mathrm{Bi}-2\},\{\mathrm{Bi}-8\}$ and $\{\mathrm{Bi}-10\}$ to construct diversity of luminescent bismuth-organic frameworks, Dalton Trans., 2013, 42(4), 1088-1093.

19 A. Thirumurugan and A. K. Cheetham, Anionic MetalOrganic Frameworks of Bismuth Benzenedicarboxylates: Synthesis, Structure and Ligand-Sensitized Photoluminescence, Eur. J. Inorg. Chem., 2010, 2010(24), 3823-3828. 
20 X. Yu, H. Zhang, Y. Cao, Z. Hu, Y. Chen and Z. Wang, Two novel 3-D bismuth oxalates with organic amines protruding in channels, J. Solid State Chem., 2006, 179(10), 30953100 .

21 M. Feyand, M. Köppen, G. Friedrichs and N. Stock, Bismuth Tri- and Tetraarylcarboxylates: Crystal Structures, In Situ X-ray Diffraction, Intermediates and Luminescence, Chem. - Eur. J., 2013, 19(37), 12537-12546.

22 J. R. Sorg, T. Schneider, L. Wohlfarth, T. C. Schäfer, A. Sedykh and K. Müller-Buschbaum, $\mathrm{Sb}-$ and Bi-based coordination polymers with $\mathrm{N}$-donor ligands with and without lone-pair effects and their photoluminescence properties, Dalton Trans., 2020, 49(15), 49044913.

23 A. K. Adcock, B. Gibbons, J. D. Einkauf, J. A. Bertke, J. F. Rubinson, D. T. de Lill and K. E. Knope, Bismuth(III)thiophenedicarboxylates as host frameworks for lanthanide ions: synthesis, structural characterization, and photoluminescent behavior, Dalton Trans., 2018, 47(38), 1341913433.

24 A. Vogler and H. Nikol, Photochemistry and photophysics of coordination compounds of the main group metals, Pure Appl. Chem., 1992, 64(9), 1311.

25 A. K. Adcock, R. J. Batrice, J. A. Bertke and K. E. Knope, Structural Diversity of Bismuth(III) Thiophenemonocarboxylates Isolated from Aqueous Solutions, Eur. J. Inorg. Chem., 2017, (11), 1435-1445.

26 R. Luckay, I. Cukrowski, J. Mashishi, J. H. Reibenspies, A. H. Bond, R. D. Rogers and R. D. Hancock, Synthesis, stability and structure of the complex of bismuth(III) with the nitrogen-donor macrocycle 1,4,7,10-tetraazacyclododecane. The role of the lone pair on bismuth(III) and lead(II) in determining co-ordination geometry, J. Chem. Soc., Dalton Trans., 1997, (5), 901-908.

27 G. G. Briand and N. Burford, Coordination complexes of bismuth(III) involving organic ligands with pnictogen or chalcogen donors, in Advances in Inorganic Chemistry, Academic Press, 2000, vol. 50, pp. 285-357.

28 O. Toma, N. Mercier and C. Botta, N-Methyl-4,4'-bipyridinium and N-Methyl-N'-oxide-4,4'-bipyridinium Bismuth Complexes - Photochromism and Photoluminescence in the Solid State, Eur. J. Inorg. Chem., 2013, 2013(7), 11131117.

29 C. S. Cunha, M. Köppen, H. Terraschke, G. Friedrichs, O. L. Malta, N. Stock and H. F. Brito, Luminescence tuning and single-phase white light emitters based on rare earth ions doped into a bismuth coordination network, J. Mater. Chem. C, 2018, 6(46), 12668-12678.

30 A. Thirumurugan, W. Li and A. K. Cheetham, Bismuth 2,6-pyridinedicarboxylates: Assembly of molecular units into coordination polymers, $\mathrm{CO} 2$ sorption and photoluminescence, Dalton Trans., 2012, 41(14), 41264134.

31 S. A. Adonin, M. N. Sokolov, M. E. Rakhmanova, A. I. Smolentsev, I. V. Korolkov, S. G. Kozlova and V. P. Fedin, Luminescent properties of 4,4-bipyridinium chlorobismuthate salt: Strong influence of solvation, Inorg. Chem. Commun., 2015, 54, 89-91.

32 G. Accorsi, A. Listorti, K. Yoosaf and N. Armaroli, 1,10Phenanthrolines: versatile building blocks for luminescent molecules, materials and metal complexes, Chem. Soc. Rev., 2009, 38(6), 1690-1700.

33 H.-R. Mürner, E. Chassat, R. P. Thummel and J.-C. G. Bünzli, Strong enhancement of the lanthanidecentred luminescence in complexes with 4-alkylated 2,2';6',2"-terpyridines, J. Chem. Soc., Dalton Trans., 2000, (16), 2809-2816.

34 X.-P. Zhang, D.-G. Wang, Y. Su, H.-R. Tian, J.-J. Lin, Y.-L. Feng and J.-W. Cheng, Luminescent 2D bismuthcadmium-organic frameworks with tunable and white light emission by doping different lanthanide ions, Dalton Trans., 2013, 42(29), 10384-10387.

35 H.-X. Qi, H. Jo, X. Chen, J. Hong and K. M. Ok, SecondHarmonic Generation and Photoluminescence Properties of $\mathrm{Sn}(\mathrm{II})$ - and $\mathrm{Bi}(\mathrm{III})$-Based Lone Pair Cation-Pyridine Dicarboxylate Coordination Compounds, Inorg. Chem., 2020, DOI: 10.1021/acs.inorgchem.0c01358.

36 R. L. Ayscue, C. P. Verwiel, J. A. Bertke and K. E. Knope, Excitation-Dependent Photoluminescence Color Tuning in Lanthanide-Organic Hybrid Materials, Inorg. Chem., 2020, 59(11), 7539-7552.

37 R. J. Batrice, R. L. Ayscue III, A. K. Adcock, B. R. Sullivan, S. Y. Han, P. M. Piccoli, J. A. Bertke and K. E. Knope, Photoluminescence of Visible and NIR-Emitting Lanthanide-Doped Bismuth-Organic Materials, Chem. Eur. J., 2018, 24(21), 5630-5636.

38 R. J. Batrice, J. A. Ridenour, R. L. Ayscue III, J. A. Bertke and K. E. Knope, Synthesis, structure, and photoluminescent behaviour of molecular lanthanide-2-thiophenecarboxylate-2,2':6',2"-terpyridine materials, CrystEngComm, 2017, 19(35), 5300-5312.

39 K. P. Carter, C. H. F. Zulato and C. L. Cahill, Exploring supramolecular assembly and luminescent behavior in a series of RE-p-chlorobenzoic acid-1,10-phenanthroline complexes, CrystEngComm, 2014, 16(44), 1018910202.

40 K. P. Carter, K. E. Thomas, S. J. A. Pope, R. J. Holmberg, R. J. Butcher, M. Murugesu and C. L. Cahill, Supramolecular Assembly of Molecular Rare-Earth-3,5-Dichlorobenzoic Acid-2,2':6',2"-Terpyridine Materials: Structural Systematics, Luminescence Properties, and Magnetic Behavior, Inorg. Chem., 2016, 55(14), 6902-6915.

41 C. Janiak, A critical account on $\pi-\pi$ stacking in metal complexes with aromatic nitrogen-containing ligands, J. Chem. Soc., Dalton Trans., 2000, (21), 3885-3896.

42 G. A. Bowmaker, F. M. M. Hannaway, P. C. Junk, A. M. Lee, B. W. Skelton and A. H. White, Synthetic, Structural and Vibrational Spectroscopic Studies in Bismuth(III) Halide/ $\mathrm{N}, \mathrm{N}^{\prime}$-Aromatic Bidentate Base Systems. V Bismuth(III) Halide/N,N'-Bidentate Ligand (1:2) Systems, Aust. J. Chem., 1998, 51(4), 325-330.

43 SAINT, Bruker AXS Inc., Madison, WI, USA, 2007. 
44 A. R. Fox, S. C. Bart, K. Meyer and C. C. Cummins, Towards uranium catalysts, Nature, 2008, 455(7211), 341-349.

45 G. Sheldrick, A short history of SHELX, Acta Crystallogr., Sect. A: Found. Crystallogr., 2008, 64(1), 112-122.

46 L. J. Farraguia, J. Appl. Crystallogr., 2012, 45, 849-845.

47 A. Spek, Structure validation in chemical crystallography, Acta Crystallogr., Sect. D: Biol. Crystallogr., 2009, 65(2), 148155.

48 F. Neese, Software update: the ORCA program system, version 4.0, Wiley Interdiscip. Rev.: Comput. Mol. Sci., 2018, 8, e1327.

49 Neese, F. 4.3, 2019.

50 T. Yanai, D. P. Tew and N. C. Handy, Chem. Phys. Lett., 2004, 393, 51-57.

51 F. Weigend and R. Ahlrichs, Balanced basis sets of split valence, triple zeta valence and quadruple zeta valence quality for $\mathrm{H}$ to $\mathrm{Rn}$ : Design and assessment of accuracy, Phys. Chem. Chem. Phys., 2005, 7(18), 3297-3305.

52 B. Metz, H. Stoll and M. Dolg, Small-core multiconfiguration-Dirac-Hartree-Fock-adjusted pseudopotentials for post-d main group elements: Application to $\mathrm{PbH}$ and $\mathrm{PbO}$, J. Chem. Phys., 2000, 113(7), 2563-2569.

53 F. Neese, F. Wennmohs, A. Hansen and U. Becker, Efficient, approximate and parallel Hartree-Fock and hybrid DFT calculations. A 'chain-of-spheres' algorithm for the Hartree-Fock exchange, Chem. Phys., 2009, 356(1), 98109.

54 T. Petrenko, S. Kossmann and F. Neese, Efficient timedependent density functional theory approximations for hybrid density functionals: Analytical gradients and parallelization, J. Chem. Phys., 2011, 134(5), 054116.

55 C. Bannwarth and S. Grimme, Comput. Theor. Chem., 2014, 1040, 45-53.

56 S. Grimme, A simplified Tamm-Dancoff density functional approach for the electronic excitation spectra of very large molecules, J. Chem. Phys., 2013, 138(24), 244104.

57 T. Risthaus, A. Hansen and S. Grimme, Excited states using the simplified Tamm-Dancoff-Approach for range-separated hybrid density functionals: development and application, Phys. Chem. Chem. Phys., 2014, 16(28), 1440814419.

58 G. te Velde, F. M. Bickelhaupt, E. J. Baerends, C. Fonseca Guerra, S. J. A. van Gisbergen, J. G. Snijders and T. Ziegler, Chemistry with ADF, J. Comput. Chem., 2001, 22(9), 931967.

59 C. Fonseca Guerra, J. G. Snijders, G. te Velde and E. J. Baerends, Towards an order-N DFT method, Theor. Chem. Acc., 1998, 99(6), 391-403.

60 E. J. Baerends, T. Ziegler, A. J. Atkins, J. Autschbach, O. Baseggio, D. Bashford, A. Bérces, F. M. Bickelhaupt, C. Bo, P. M. Boerrigter, L. Cavallo, C. Daul, D. P. Chong, D. V. Chulhai, L. Deng, R. M. Dickson, J. M. Dieterich, D. E. Ellis, M. van Faassen, L. Fan, T. H. Fischer, A. Förster, C. Fonseca Guerra, M. Franchini, A. Ghysels, A. Giammona, S. J. A. van Gisbergen, A. Goez, A. W. Götz, J. A. Groeneveld, O. V. Gritsenko, M. Grüning, S. Gusarov,
F. E. Harris, P. van den Hoek, Z. Hu, C. R. Jacob, H. Jacobsen, L. Jensen, L. Joubert, J. W. Kaminski, G. van Kessel, C. König, F. Kootstra, A. Kovalenko, M. V. Krykunov, E. van Lenthe, D. A. McCormack, A. Michalak, M. Mitoraj, S. M. Morton, J. Neugebauer, V. P. Nicu, L. Noodleman, V. P. Osinga, S. Patchkovskii, M. Pavanello, C. A. Peeples, P. H. T. Philipsen, D. Post, C. C. Pye, H. Ramanantoanina, P. Ramos, W. Ravenek, J. I. Rodríguez, P. Ros, R. Rüger, P. R. T. Schipper, D. Schlüns, H. van Schoot, G. Schreckenbach, J. S. Seldenthuis, M. Seth, J. G. Snijders, M. Solà, M. Stener, M. Swart, D. Swerhone, V. Tognetti, G. te Velde, P. Vernooijs, L. Versluis, L. Visscher, O. Visser, F. Wang, T. A. Wesolowski, E. M. van Wezenbeek, G. Wiesenekker, S. K. Wolff, T. K. Woo and A. L. Yakovlev, Vrije Universiteit, Amsterdam, The Netherlands, http:// www.scm.com, 2019.

61 M. P. Mitoraj, A. Michalak and T. Ziegler, A Combined Charge and Energy Decomposition Scheme for Bond Analysis, J. Chem. Theory Comput., 2009, 5(4), 962-975.

62 M. P. Mitoraj, A. Michalak and T. Ziegler, On the Nature of the Agostic Bond between Metal Centers and $\beta$-Hydrogen Atoms in Alkyl Complexes. An Analysis Based on the Extended Transition State Method and the Natural Orbitals for Chemical Valence Scheme (ETS-NOCV), Organometallics, 2009, 28(13), 3727-3733.

63 W. Frank and V. Reiland, Heavy-Metal [pi] Complexes. 13. Trichloro(1,2,3-trimethylbenzene)bismuth(III), Acta Crystallogr., Sect. C: Cryst. Struct. Commun., 1998, 54(11), 16261628.

64 W. Zhang and Y.-Q. Feng, A novel dinuclear bismuth(III) coordination compound: bis([mu]-pyridine-2,6-dicarboxylato)-[kappa]4O2,N,O6:O6';[kappa]4O2:O2',N,O6-bis[(azido[kappa]N)(1,10-phenanthroline-[kappa]2N,N')bismuth(III)] tetrahydrate, Acta Crystallogr., Sect. C: Struct. Chem., 2014, 70(6), 562-565.

65 K. M. Lewis, J. Kelley, L. Peterson, M. D. Smith, R. C. Severance, S. A. Vaughn and H.-C. Z. Loye, Synthesis and Crystal Structure of an Iodobismuthate Incorporating Both a Cationic and Anionic Bi(III) Complex Ion, J. Chem. Crystallogr., 2010, 40(10), 867-871.

66 C. L. Raston, G. L. Rowbottom and A. H. White, Structural studies of Group 5B-halide-dithio-ligand complexes. Part 7. Crystal structures of the 1:1 adducts of (NN-diethyldithiocarbamato)-di-iodobismuth(III) with 2,2'-bipyridyl and 2,2':6',2'-terpyridyl, Dalton Trans., 1981, (6), 1383-1388.

67 M. A. Tershansy, A. M. Goforth, M. D. Smith and H.-C. zur Loye, The Synthesis and Crystal Structure of [BiI2(tpy) 2][Bi2I7(tpy)]: A New Metal Halide Material, J. Chem. Crystallogr., 2008, 38(6), 453-459.

68 P. C. Junk and L. M. Louis, Dimeric Structure of [( $12-\mathrm{NO} 3)$ 2(tpy)Bi( $\mu-\mathrm{OH}) 2 \mathrm{Bi}(\mathrm{tpy})(\eta 2-\mathrm{NO} 3) 2]$, Z. Anorg. Allg. Chem., 2000, 626(2), 556-559.

69 W. J. Evans, J. H. Hain and J. W. Ziller, Synthesis and first X-ray crystal structure of a $\mathrm{Bi}(\mathrm{OR})_{3}$ complex: tris(2,6-dimethylphenoxo)bismuth, J. Chem. Soc., Chem. Commun., 1989, (21), 1628-1629. 
70 Z. Ouerghi, H. Gornitzka, E. Temel, I. Dridi and R. Kefi, A new non-centrosymmetric Chlorobismuthate(III) hybrid material: Crystal structure, optical properties and antibacterial study, J. Mol. Struct., 2019, 1181, 338-347.
71 H. D. Yin, C. H. Wang and Q. J. Xing, Synthesis and Crystal Structure of Bismuth(III) Complexes $\mathrm{Bi}(1,10-$ phen) $\left[\mathrm{S}_{2} \mathrm{CN}\left(\mathrm{CH}_{3}\right)_{2}\right]_{2}\left(\mathrm{NO}_{3}\right),\left\{\mathrm{Bi}\left(\mathrm{S}_{2} \mathrm{COCH}_{2}\right)\left[\mathrm{S}_{2} \mathrm{CNC}_{6} \mathrm{H}_{5}\left(\mathrm{CH}_{3}\right)\right]_{2}\right\}_{2}$ and $\left[\mathrm{Bi}\left(\mathrm{S}_{2} \mathrm{CNBu}_{2}\right)_{2}\left(\mathrm{CH}_{3} \mathrm{OH}\right)\left(\mathrm{NO}_{3}\right)\right] \infty$, Chin. J. Chem., 2005, 23(12), 1631-1636. 